Eduardo Silva Arévalo, S.J.

Profesor de la Facultad de Teología

Pontificia Universidad Católica de Chile

\title{
Paul Ricoeur y los desplazamientos de la hermenéutica
}

Nuestro propósito es mostrar los desarrollos y aportes que Paul Ricoeur ofrece a la filosofía hermenéutica contemporánea. Deudor confeso del sitial en que la tradición hermenéutica ha sido colocada gracias a la reflexión de Heidegger y Gadamer, siguiendo la senda iniciada por Schleiermacher y Dilthey (1), Ricoeur es también un innovador que se apropia críticamente de la tradición de sus antecesores. Reconociendo la continuidad evidente y la progresiva evolución respecto de estos, nos interesa subrayar los aspectos distintivos de su fenomenología hermenéutica. Será justamente su filiación husserliana la que le permite una distancia que nos hace estimar que es un cierto "desplazamiento de la hermenéutica" (2) su aporte más característico. Ello por varias razones.

En primer lugar, más allá de las semejanzas, el aire de familia y a veces la total cercanía entre nociones de Gadamer y Ricoeur que parecen indiscernibles, el paso de uno a otro o su diferencia, tiene que ver con la inclusión o irrupción de un momento crítico en la hermenéutica. Las nociones ricoeurianas de distanciamiento, las preocupaciones epistemológicas y de método, la vuelta al texto como paradigma, y en definitiva, su insistencia en superar la inmediatez y autotransparencia de un sujeto abstracto -obligado a hacer el largo rodeo por los símbolos y los textos para una apropiación de sí mismo mediada y concreta- hablan más bien de una reorientación y un desplazamiento, que de una pacífica evolución.

En segundo lugar, acorde con esta preocupación epistemológica, la voluntad de diálogo tan propia de la hermenéutica se ejerce en un interés por debatir con todas las disciplinas y pensamientos contemporáneos. Muy lejos de ser un pensador que avanza solo por senderos privados y herméticos, de espaldas a su tiempo, su itinerario filosófico da testimonio de su exposición a todos los tráficos, siempre intentando mediar, arbitrando conflictos, incorporando la riqueza de las visiones aun las más

(1) De ello se ocuparon las dos primeras ponencias que inauguraron este Seminario sobre "La hermenéutica y su impacto en la teología" que ofrecieron los profesores Mariano de la Maza y Alejandro Vigo. El trabajo de este último, aquí publicado, insiste no solo en los cambios que han afectado a la propia teoría de la interpretación, sino en la transformación y reformulación hermenéutica de la racionalidad contemporánea. Respecto de las deudas de Ricoeur con su tradición ver Ricoeur, "La tâche de 1'herméneutique: en venant de Schleiermacher et de Dilthey" (1975), en Du texte à l'action. Essaias d'hermèneutique, Seuil, Paris, 1986, 75-100.

(2) El término es también usado por Werner Jeanrond, "Les déplacements de 1'hermenéutique au XXe siecle", en Pierre Bühler et Clairette Karakassh, Quand interpréter c'est changer. Pragmatique el tectures de la Parole (Actas congreso Neuchâtel 1994), Labor et Fides, Geneve, 1995. 
opuestas. Ricoeur estima que la filosofía no puede volverse sobre sí misma, en una especie de 'filosofía sobre la filosofía' (3), y por el contrario ha incursionado en la fenomenología de la religión, en el psicoanálisis, en la lingüística, en la historiografía, en la exégesis bíblica, en la jurisprudencia e incluso en las neurociencias. Un filósofo así expuesto no evoluciona internamente, sino que se ve tironeado, desplazado, llevado de un lugar a otro y con él su pensamiento.

En tercer lugar, el propio itinerario de Ricoeur -como tendremos oportunidad de apreciarlo- no es el desenvolvimiento, en un desarrollo continuo, de una idea prevista. A menudo se sorprende con los intérpretes que dan unidad a su pensamiento o que descubren los hilos conductores de su obra. Alguien que rechaza el sistema, cuya filosofía es todo lo contrario de un saber absoluto, sostiene que cada libro procede de un residuo del precedente, de una cuestión no resuelta, de algo que ha quedado ahí como pregunta y pide ser investigado. El carácter fragmentario que él mismo percibe en su obra tiene que ver con esto de desplazarse de residuo en residuo (4).

Abordaremos en cinco acápites estos desplazamientos. Los tres primeros se ocupan de mostrar los desplazamientos que ha provocado en las tradiciones de las que nuestro filósofo se siente deudor. En primer lugar la tradición reflexiva salida de Descartes que, por los años sesenta ha recibido el fuego cruzado del psicoanálisis y del estructuralismo cuestionando un sujeto que después de la batalla queda -al decir de Ricoeur- como un Cogito 'herido'. En segundo lugar los cuestionamientos a la tradición hermenéutica nuevamente combatida desde dos frentes, la teoría crítica y la deconstrucción. Modernos y posmodernos critican por igual una tradición filosófica que Schleiermacher y Dilthey comenzaron -al transformar la que era una modesta disciplina auxiliar para interpretar textos bíblicos, literarios y jurídicos- y que Heidegger y Gadamer continuaron, convirtiéndose en puntos de referencia obligados de su desarrollo. Tales críticas, a menudo certeras, obligan a Ricoeur ha diferenciarse -a efectuar un nuevo desplazamiento- respecto de la concepción hermenéutica que proponen este par de pensadores, "los más emblemáticos de la tradición centroeuropea contemporánea" (5). En tercer lugar los desplazamientos que el propio Ricoeur ha hecho respecto de la fenomenología, y que pueden ser presentados desde dos movimientos que le son característicos: la incorporación en su filosofía del giro lingüístico y el injerto de la hermenéutica en el método fenomenológico. Son estos desplazamientos respecto de las propias tradiciones que lo constituyen -reflexiva, hermenéutica, fenomenológica- los que nos permiten abordar en el cuarto acápite una adquisición fundamental de su filosofía hermenéutica y que se constituye en un aporte insustitui-

(3) Ricoeur, "De la volonté á l'acte" (1990), 'Temps et récit' de Paul Ricoeur en débat, Edited by Ch. Bouchindhomme y R. Rochlitz, Paris, Cerf, 1990, 23.

(4) Cf. Ricoeur, "Autocomprensión e historia" (1987), en Paul Ricoeur: Los caminos de la interpretación, Tomás Calvo Martínez, Remedios Avila Crespo (eds.), Anthropos, Barcelona, 1991, 28.

(5) A. Vigo, "Caridad, sospecha y verdad. La idea de racionalidad en la hermenéutica filosófica contemporánea”, en este mismo numero, pág. 254. Según Vigo la transformación hermenéutica de la filosofía continental que ellos han llevado a cabo, radicalizando la problemática de la comprensión, se ha verificado también más allá de los límites de dicha tradición en el giro hermenéutico que pensadores como Quine, Davidson, Rorty y Pultmam han dado a la tradición analítica anglosajona. La sensibilidad que Ricoeur tiene respecto de esta última y la apropiación que efectúa de la filosofía del lenguaje será un factor no menor en su desplazamiento. 
ble para todas aquellas disciplinas -entre ellas la teología- que viven interpretando: el desplazarse desde una hermenéutica del autor a una hermenéutica del lector que actualiza el texto en el acto de lectura (6). Finalmente, en el quinto acápite, abordamos algunas de las consecuencias de este desplazamiento, mostrando que Ricoeur contribuye a abrir una vía intermedia entre un sentido único y fijo para siempre y sentidos infinitos inconmensurables entre sí, un camino que nos permite superar el objetivismo moderno evitando el relativismo posmoderno.

\section{EL CUESTIONAMIENTO DE LA TRADICIÓN REFLEXIVA: EL SUJETO PUESTO EN CUESTIÓN}

El filósofo Jean Greisch sostiene que el pensamiento de Ricoeur 'es una casa con ventanas'. Hermosa metáfora para un pensador genuinamente multidisciplinar, testigo y participante del debate intelectual desde la posguerra. Actitud coherente con quien sostiene que la filosofía no comienza nada sino que piensa a partir de otro. Pero una actitud arriesgada si se está en París, capital de la moda, en un tiempo en que las modas intelectuales han sido tan avasalladoras como fugaces. La segunda mitad del siglo ha sido sacudida por huracanes bruscos, tan intensos como breves, que se han sucedido unos a otros con más rapidez que lo que requiere el pensar. "El triángulo marxismo/existencialismo/personalismo" que ha influido todo el pensamiento de posguerra "ha casi completamente desaparecido" (7). Del personalismo pocos se acuerdan; el existencialismo murió con Sartre y mayo del 68 fue su canto de cisne; veinte años después hemos sido testigos, con la caída del muro, del derrumbe del socialismo soviético y -parece- del marxismo. Estos tres gigantes en declive debieron ceder su lugar en los años sesenta al estructuralismo y al psicoanálisis. Pero las versiones más omnicomprensivas de Lévi-Strauss y Lacan, que en su momento conquistaban la mayoría de los espíritus, parecen ya haber quedado en el camino. Luego han llegado los sostenedores de la hermenéutica heideggeriana, los modernos de la escuela de Frankfurt y finalmente los deconstructivistas de la posmodernidad. Cada uno de ellos se ha autoproclamado como los sepultureros respectivos de la metafísica occidental, de la razón instrumental o de la modernidad (8).

Con todos ellos Ricoeur ha entrado en diálogo, en un intento por asumir con honestidad intelectual admirable hasta las posturas más alejadas. No siempre ha sido tratado con la misma cordialidad que él dispensa. No pocas veces su condición de creyente ha sido causa de durísimas intolerancias en su contra. Pero dejemos que

(6) Para una explicitación de las consecuencias teológicas de este desplazamiento desde el polo autor-texto al polo texto-lector remito al apartado "Algunos aportes de Ricoeur a la teoría hermenéutica" de la lección inaugural del año académico 2004 de la Facultad de Teología, "La teología en la edad hermenéutica de la razón", que será publicado en un próximo número de Teología y Vida. Para algunos desarrollos de los puntos aquí abordados ver Eduardo Silva, Poética del relato y poética teológica. Aportes de la hermenéutica filosófica de Paul Ricoeur en Temps et récit para una hermenéutica teológica, Anales de la Facultad de Teología PUCCh, Santiago, 2000.

(7) Ricoeur, "Nous ne sommes pas responsables de nos contemporains" (1990), (entrevista por E. Denimal) en Le Christianisme au XXe siècle 1990, No 245, 10 février, 8.

(8) Cf. Alain Thomasset, Paul Ricoeur. Une poétique de la morale, Press Universitaires de Louvain, Louvain, 1996, 53. 
sean sus propias palabras las que nos digan cómo ha atravesado estas modas culturales, estos momentos filosófico-culturales, estos pensamientos que parecían tan hegemónicos y que cada uno en su momento prometía un reinado eterno.

"He atravesado cuatro paisajes filosóficos. Al comienzo de mi enseñanza, hasta alrededor de los años 50-55, este paisaje era determinado por la oposición existencialismo-marxismo; el segundo periodo ha sido marcado por el estructuralismo, en particular por el análisis estructural de las religiones que operaba Claude LéviStrauss; un tercer periodo está dominado por la figura de Nietzsche, el tema de la muerte de Dios con el trasfondo de una cierta muerte del hombre. Este nihilismo de los valores conduce a un cuarto periodo que me cuesta más caracterizar, justamente porque estoy en él y al ser un objeto que está demasiado cerca no distingo claramente las líneas. Es en suma a través de estos cuatro paisajes donde cada vez el "sujeto" era o está en cuestión, que he tratado de desarrollar una problemática de la persona con esta regla que me he siempre impuesto: tratar de transformar un obstáculo en apoyo" (9).

Frente a este panorama complejo, dirigiremos la mirada al modo como Ricoeur enfrenta dos posiciones de pensamiento con las que se ve confrontado después de publicar La simbólica del mal en 1960. Se abre un periodo que califica de "polémicas exteriores y de guerras intestinas" (10) que durará hasta que a fines de los años setenta se produzca el cambio de los paradigmas filosóficos franceses.

\section{1) La cuestión del psicoanálisis}

Llevado por el tema de la culpa incursiona exhaustivamente en el psicoanálisis y descubre que la hermenéutica inaugurada por Freud en La interpretación de los sueños (1900), que luego se desplegara en una verdadera filosofía de la cultura, era una hermenéutica opuesta a la practicada por él en La simbólica del mal. El psicoanálisis daba testimonio de una interpretación 'reductiva' que se oponía a su interpretación 'amplificante' 'recuperadora' del sentido (11), e.d., "una interpretación atenta al excedente de sentido incluido en el símbolo, y que la reflexión tenía como tarea liberar, al tiempo que debía enriquecerse" (12). En el trabajo que Ricoeur dedicó a Freud, De la interpretación. Ensayo sobre Freud (1965) se empeña en reconocer la validez del psicoanálisis, asignándole la mayor potencia argumentativa antes de entablar con él una clara relación crítica. Así, primero en su 'lectura', presenta "la explicación freudiana como discurso mixto, que mezcla el lenguaje de la fuerza

(9) Ricoeur, "Nous sommes responsable du périssable" (1991), (entrevista por J.P. Manigne) en L'actualité religieuse dans le monde 1991, No 91, juillet-aôut, 41.

(10) Ricoeur, "Autobiographie intelectuelle", op. cit., 34. Al seguir de cerca este ensayo autobiográfico, se explica el uso que se hace de la primera persona. Las reflexiones ricoeurianas a propósito de este enfrentamiento cruzado con el psicoanálisis y el estructuralismo pueden encontrarse en Le Conflit des interprétations. Essais d'herméneutique, Seuil, Paris, 1969.

(11) Una autocrítica posterior reconoce que en esa época la llamo "desafortunadamente" interpretación 'recuperadora' del sentido Cf. "Autobiographie intelectuelle", 37.

(12) Ibíd. "Mucho más tarde, en la época de Tiempo y narración, vinculé a la lectura, y en general a la historia de la recepción, este fenómeno de amplificación con respecto al sentido que un texto parece haber tenido para su autor o su primer auditorio" (ibíd.). Es este el punto que abordaremos en la cuarta parte de este artículo: 'la actualización del texto en el acto de lectura'. 
(pulsión, carga, condensación, desplazamiento, represión, retorno de lo reprimido, etc.) y el del sentido (pensamiento, deseo, inteligibilidad, absurdo, disfraz, interpretación, interpolación, etc.)" (13). Discurso mixto debido a la naturaleza mixta de su objeto, situado en el punto de flexión del deseo y el lenguaje. Luego en la sección 'interpretativa' de la obra sobre Freud, confronta el discurso del psicoanálisis así reconstruido con el de la fenomenología y el de la filosofía reflexiva, y presenta "la oposición entre los dos discursos como la existente entre un movimiento regresivo, orientado hacia lo infantil, lo arcaico, y un movimiento progresivo, orientado hacia un telos de completud significante" (14). Un conflicto de las interpretaciones tomaba forma bajo los rasgos de una arqueología de la conciencia opuesta a una teleología del sentido, quedando los derechos de una y otra plenamente reconocidos y respetados. El reconocimiento del derecho igual de interpretaciones rivales formaba parte del arbitraje que podía ofrecer la reflexión filosófica. "Por un lado, Freud se inscribía en una tradición de fácil identificación, la de una hermenéutica de la sospecha que continuaba a Feuerbach, Marx y Nietzsche. Por otro, le hacían frente la filosofía reflexiva ilustrada por Jean Nabert, la fenomenología enriquecida por Merleau Ponty, la hermenéutica ilustrada y brillantemente renovada por Gadamer" (15).

\section{2) La cuestión del estructuralismo}

Quedaba por encarar el segundo frente de este conflicto de las interpretaciones: el estructuralismo. Un título globalizador para la vasta corriente lingüística surgida de Ferdinand de Saussure. "La semiología profesada por Roland Barthes, la semiótica de A.J. Greimas, la crítica literaria ilustrada por Gérard Genette, tenían en común el hecho de ajustarse únicamente a las estructuras de los textos, con exclusión de la intensión supuesta de su autor" (16). A ellos se agregaba la prestigiosa y magistral obra de Claude Lévi Strauss sobre los mitos (17), y los giros estructuralistas que tomaban tanto el marxismo con Louis Althusser, como el psicoanálisis con Lacan. "Ahora bien, no era en cuanto hermenéutica de la sospecha que el estructuralismo cuestionaba la noción de sujeto, sino en cuanto abstracción objetivante, por la cual el lenguaje se encontraría reducido al funcionamiento de un sistema de signos sin anclaje subjetivo" (18). Apoyándose en Emile Benveniste que hacía de la oración y no del signo léxico la primera unidad de sentido del lenguaje, en Roman Jakobson para definir el discurso ("alguien dice algo a alguien sobre algo según reglas") y en la distinción de G. Frege entre sentido (decir algo) y referencia (sobre algo), Ricoeur trabaja sobre la polaridad entre semántica y semiótica. "De esta polaridad de base veía derivar a las demás polaridades constitutivas de un conflicto de interpretaciones

(13) Ibíd., 38.

(14) Ibíd.

(15) Ibíd., 40

(16) Ibíd.

(17) Tristes Trópicos (1955), El pensamiento salvaje (1962) y Mitológicas I- Lo crudo y lo cocido (1964). "Estas obras daban crédito a la idea de una organización sistemática de los conjuntos míticos, y más generalmente de las estructuras lingüísticas y sociales, que sería indiferente a la búsqueda de sentido de un sujeto de angustia", tan característico de los existencialismos. "En una polémica cordial llegué a designar este pensamiento como trascendentalismo sin sujeto" (Ibíd., 34).

(18) Ibíd., 40. 
que afectan todo el imperio de las significaciones. Más netamente que entre el psicoanálisis y la fenomenología o la filosofía reflexiva, percibía, más allá del momento de antagonismo, el de mediación. El pasaje por el punto de vista objetivo y sistémico de la semiótica se convertía así en una estadía obligada para una comprensión de sí cada vez más indirecta y cada vez más sumisa al régimen de las mediaciones largas" (19).

Las mediaciones se multiplicaban y prolongaban al punto que la ambición de totalizarlas en un sistema de estilo hegeliano le parece cada vez más vana y sospechosa. "Lo que se imponía no era solo el lado indirecto y mediato de la reflexión (que se oponía a la pretensión de transparencia e inmediatez de la conciencia tanto de Descartes como de Husserl), sino su lado no totalizable y finalmente fragmentario" (20). Al aspecto conflictivo de ese Cogito 'herido' se sumará el aspecto 'fragmentario' que subrayaran sus trabajos ulteriores sobre la metáfora, la narración y el sí mismo.

\section{EL CUESTIONAMIENTO DE LA TRADICIÓN HERMENÉUTICA: CRÍTI- CA Y DECONSTRUCCIÓN}

La hermenéutica de Gadamer sostiene que el problema de la comprensión del sentido es tan universal como la filosofía misma. Basándose en la universalidad del lenguaje, comprendido como discurso, se concluye que donde hay discurso se está en presencia de un fenómeno hermenéutico. La hermenéutica llega a ser una manera de definir la tarea de la filosofía como tal (21). Universalidad que le confiere su dignidad ontológica. Heidegger ya había enseñado que la comprensión, antes de ser el origen de un saber en sentido epistemológico, es una estructura fundamental de nuestro ser-enel-mundo. Así extendida la hermenéutica filosófica, no es mas una ciencia regional que abocada sobre los textos sería "el arte de evitar los malentendidos" -como la definió Schleiermacher-, no es más una metodología de las ciencias de la interpretación, apta para las ciencias del espíritu, como la quería Dilthey. Gadamer insistirá que la hermenéutica no dicta conductas, que renuncia a un concepto normativo y regulador: "ella no dice más lo que es necesario hacer para comprender, ella dice simplemente lo que pasa cuando comprendemos efectivamente, en otras palabras, ella enuncia las condiciones de posibilidad de toda comprensión" (22).

Los cuestionamientos a este planteo han sido múltiples, y aun cuando proceden de diversos lugares, convergen en una pregunta decisiva: “QQué es de la instancia crítica que Gadamer ha apartado del campo hermenéutico?" (23). Este retorno de una instancia crítica desde contextos filosóficos diferentes, hacen que Jean Greisch diagnostique en los años setenta una "crisis de la hermenéutica" del tipo propuesto

(19) Ibíd., 41.

(20) Ibíd., 42.

(21) Cf. Jean Greisch, "La crise de l'herméneutique. Reflexions méta-critiques sur un débat actuel", en J. Greisch, K. Neufeld, C. Théobald, La crise contemporaine. Du modernisme a la crise des herméneutiques, Beauchesne, Paris, 1973.

(22) Ibíd., 144.

(23) Ibíd. 
por Gadamer. Las críticas provienen justamente de quienes pueden ser considerados familiares o herederos del psicoanálisis y del estructuralismo: la teoría crítica (de Habermas) y el neoestructuralismo (de Derrida). Las dificultades que experimenta Gadamer para afrontar tales cuestionamientos son mayores que las que padece un pensamiento hermenéutico, que como el ricoeuriano se ha constituido al fragor de tales debates. Pero lo que parece decisivo a la hora de recepcionar, con más o menos facilidad, la instancia crítica es que la propia tarea que Ricoeur se ha planteado de cara a la tradición hermenéutica consiste en preguntarse “¿Cómo es posible introducir una instancia crítica cualquiera en una conciencia de pertenencia expresamente definida por el rechazo de la distanciación?" (24).

\section{1) Hermenéutica y teoría crítica}

a) La crítica de Habermas a Gadamer. Desde el contexto anglosajón el cuestionamiento ha venido del último de los portavoces de la escuela neomarxista de Frankfurt. Habermas cuestiona la pretensión de universalidad de la hermenéutica gadameriana. "Hermenéutica y crítica de las ideologías aparecen como dos maneras diferentes e irreductibles de definir la tarea filosófica en la época poshegeliana. Por ello el eje del enfrentamiento es una cierta determinación de la tarea filosófica como tal (que pasa por) cuestionar la universalidad del punto de vista opuesto" (25). El interés de Habermas es hacer valer en la filosofía contemporánea, la exigencia crítica inaugurada por la Aufklärung. La crítica de la ideologías significa un cierto fracaso de la hermenéutica, contesta su reivindicación de universalidad y la reenvía a sus propios límites. "La hermenéutica es incapaz de dar cuenta de todos los casos de seudocomunicación, e.d., de todos los casos de una comunicación sistemáticamente deformada. La hermenéutica tratará estas seudocomunicaciones como comunicaciones auténticas" (26). Aquí el psicoanálisis juega un rol paradigmático, al denunciar la "conciencia falsa". La hermenéutica, para quien todo diálogo es transparente, es impotente frente a esta situación. "La opacidad específica de este discurso y el malentendido que lo constituye, le son inaccesibles, tratará la conciencia falsa como si ella fuera conciencia auténtica" (27). La tarea de la crítica de las ideologías es análoga respecto a las deformaciones propias de la tradición. "El 'diálogo que nosotros somos' (Hölderling) es siempre ya un diálogo desfigurado y deformado, porque él está investido por relaciones de fuerzas que nos vienen de la tradición. La violencia no esta excluida del universo hermenéutico. Pero el pensamiento hermenéutico, por su consentimiento incondicional a la tradición, se priva de todo medio para desenmascarar esta violencia. Por ello corre el riesgo de funcionar como una legitimación suplementaria. En razón de este peligro ella debe ser superada por la reflexión crítica, que somete todo diálogo efectivo al criterio utópico de una comunicación universal, liberada de toda restricción y de toda violencia” (28).

(24) Ricoeur, "La fonction herméneutique de la distanciation" (1975), Du Texte a l'action, Seuil, Paris, 1986, 99.

(25) J. Greisch, art. cit., 146.

(26) Ibíd., 149.

(27) Ibíd., 150.

(28) Ibíd. 
Hasta aquí la crítica de Habermas a Gadamer. Nos interesa ahora asomarnos al modo como Ricoeur recepciona este cuestionamiento.

b) Ricoeur entre Habermas y Gadamer. Una buena introducción en el aporte ricoeuriano al famoso debate de la década del setenta entre Gadamer y Habermas, nos lo ofrece un párrafo que le dedica en Temps et récit.

"No pretendo atenuar el conflicto entre hermenéutica de las tradiciones y crítica de las ideologías; su 'ambición de universalidad' - para retomar el tema de una controversia entre Gadamer y Habermas, consignado en el volumen Hermeneutik und Ideologiekritik, Francfort, Suhrkamp, 1971- procede de dos 'lugares diferentes': la reinterpretación de los textos recibidos de la tradición, en uno, y la crítica de las formas sistemáticamente alteradas de la comunicación, en el otro. Por eso, no se puede simplemente superponer lo que Gadamer llama pre-juicio, que es un prejuicio favorable, y lo que Habermas llama ideología, que es una distorsión sistemática de la competencia comunicativa. Se puede solamente mostrar que, hablando de dos lugares diferentes, cada uno debe integrar un segmento del argumento del otro. Es lo que intento demostrar en "Herméneutique et critique des idéologies"” (29).

Para Ricoeur lo que está en juego en este debate es el gesto filosófico de base: entre el gesto hermenéutico del humilde reconocimiento de las condiciones históricas a las que estamos sometidos y el gesto crítico, gesto fiero de desafío dirigido contra las distorsiones de la comunicación humana (30). Una nueva actualización de la clásica pugna entre el romanticismo y la ilustración (31). El punto nuclear que Habermas objeta a Gadamer tiene directa relación con nuestro tema de la tradición. El ataque a Gadamer se centra en su concepción de la conciencia histórica y su rehabilitación provocadora de los conceptos de prejuicio, de autoridad y de tradición (32).

Ricoeur, luego de presentar las posturas de cada uno como alternativas incompatibles (33), se aboca a estudiar las condiciones que permiten reconocer al otro al interior de su propia postura. Analiza cómo de hecho está integrado el momento crítico en la hermenéutica y cómo está integrado el momento hermenéutico en la crítica de las ideologías (34).

Los déficit críticos de la concepción hermenéutica tanto de Heidegger como de Gadamer quedan en evidencia. Las preocupaciones ontológicas no deben prescindir de las consideraciones epistemológicas, la cuestión de la 'verdad' no se opone a la cuestión del 'método'. El aporte de Ricoeur a la reflexión hermenéutica dice relación con el reconocimiento de que no toda distanciación es alienante, sino que por el contrario es condición de posibilidad de cualquier comunicación (35). Comunicación en la distancia y gracias a la distancia, carácter paradigmático del texto, y del

(29) Ricoeur, Temps et Récit III, 325-326.

(30) Cf. "Herméneutique et critique des idéologies" (1973), Du Texte a l'action, 333; 362.

(31) Cf. Ibíd., 376.

(32) Cf. Ibíd., 335

(33) Cf. 'Gadamer : 1'herméneutique des traditions', Ibíd., 335-351; 'Habermas: la critique des idéologies', Ibíd., 351-361.

(34) "A quelle condition une philosophie herméneutique peut-elle rendre compte en elle-même de la requête d'une critique des ideologies? Au prix de quelle reformulation ou de quelle refonte de son programme? A quelle condition une critique des idéologies est-elle possible? peut-elle être, en dernière analyse, dénuée de présupposés herméneutiques?" (Ibíd., 362). Cf. "La fonction herméneutique de la distanciation", art. cit., 98 
texto escrito, abordable como objeto de ciencias, que "imponen una fase explicativa en el corazón mismo de la comprensión" (36); nuevo desvío, nuevo rodeo -digamos desplazamiento- por procedimientos pertenecientes al análisis objetivo y a la explicación al abordar la textualidad misma de los textos (37). El momento crítico en la hermenéutica implica reconocer tanto el aporte de la explicación a la comprensión, como el de la sospecha a la apropiación y ampliación del sentido.

Por otra parte, Ricoeur muestra con bastante claridad que la propia "crítica es también una tradición" (38). Es imposible saltarse la historia y ubicarse en un nolugar, libre de prejuicios, no afectado por ningún sesgo ideológico. Siempre hablamos desde una tradición. La crítica de las ideologías pertenece a la tradición de la Aufklärung. Ella habla más bien desde la tradición de la emancipación que de la tradición de la rememoración, del romanticismo, que sería la tradición a la que pertenece Gadamer. La crítica hunde sus raíces en la más impresionante tradición, aquella de los actos liberadores; a ella pertenecen también la memoria del Éxodo y la memoria de la Resurrección (39).

\section{2) Hermenéutica y deconstrucción}

a) El desencuentro entre Derrida y Gadamer. La tentativa de confrontar hermenéutica y deconstrucción (gramatología (40)) presenta más riesgos que el debate anterior. "Todo diálogo entre pensamientos supone un mínimo de acuerdo previo: ahora bien es precisamente ese mínimo de acuerdo que hace aquí objeto de la contestación" (41). Como el diálogo entre ambos prácticamente no ha tenido lugar se puede reflexionar sobre sus condiciones de imposibilidad. Se puede mostrar porque el encuentro entre hermenéutica y gramatología "debe tomar necesariamente la forma de una lucha a muerte, de un enfrentamiento que excluye de pronto toda posibilidad de una reconciliación o de una mediación" (42). La razón profunda de la incompatibilidad radical entre los dos pensamientos consiste en que la gramatología, al rechazar ser la inversión simple de una problemática metafísica opera por desplazamientos de las preguntas y borra el horizonte mismo a partir del cual una hermenéutica deviene pensable. "El privilegio hermenéutico de la pregunta (...), la lógica de la pregunta y de la respuesta, es impensable sin un privilegio acordado al diálogo y a la viva voz. La gramatología es la contestación radical, iconoclasta, de este prestigio de la viva voz en nombre de la escritura" (43). No es que se ponga en cuestión una teoría del lenguaje, sino el conjunto de la filosofía. "La hermenéutica quiere decir la esencia de la filosofía, la gramatología, inscribiéndose al margen de aquella, demuestra el límite" (44).

(36) "Autobiographie intelectuelle", art. cit., 52.

(37) Cf. Ibíd., 53.

(38) "Herméneutique et critique des idéologies", art. cit., 376.

(39) Cf. Ibíd.

(40) Cf. J. Greisch, Herméneutique et grammatologie, Cerf, Paris, 1977.

(41) J. Greisch, art. cit., 157.

(42) Ibíd.

(43) Ibíd., 158-159.

(44) Ibíd., 159. 
La relación a la herencia común heideggeriana, no soluciona el diferendo, pues mientras Derrida radicaliza las afirmaciones de Heidegger relativas a la deconstrucción de la metafísica de la presencia, Gadamer procura atenuarlas en nombre de la continuidad hermenéutica. La deconstrucción de la metafísica bajo todas sus formas implica necesariamente la deconstrucción de la hermenéutica. Más aún si se estima que esta última "no es más que una tentativa desesperada de salvaguardar, bajo la apariencia de una filosofía de la finitud no hegeliana, lo esencial del aparato ontoteológico" (45). Pues lo que la gramatología tiene por tarea deconstruir es el logocentrismo y el fonocentrismo de la época metafísica como tal. Logocentrismo que reposa a su vez sobre la onto-teo-logía. "El proyecto de la gramatología está ligado a la tentativa de superar la ontoteología en sus expresiones las más ocultas en dirección de un pensamiento de la diferencia" (46).

Hasta aquí el desencuentro entre Derrida y Gadamer. Antes de pasar a algunas tomas de postura de Ricouer frente a la cuestión, conviene atender a la evaluación que Jean Grondin, biógrafo e intérprete de Gadamer, hace de este desencuentro.

Derrida sostiene que los textos remiten solo a otros textos, de significantes a significantes, de manera análoga a como Nietzsche sostenía que no hay hechos sino solo interpretaciones. En un encuentro entre Gadamer y Derrida en París en 1981 (47), este último se pregunta si se puede hablar de una comprensión de la verdad. “ ¿No habría que admitir que el entender va a la deriva de un signo a otro sin topar jamás con algún sentido que podría ser algo así como una presencia corpórea? (...) un signo debe "querer" decir algo, pero no se puede averiguar del todo que es lo que quiere decir. Así, la presencia exigida de sentido siempre queda "diferida", de manera que para Derrida todos los signos están animados por una differance nunca alcanzada" (48). Grondin intenta tomar en serio el planteo y no despacharlo apresuradamente. "Se puede responder con desdén a esta objeción y señalar simplemente que el hecho innegable de que la capacidad de entender existe como principio y que también Derrida quiere entender y ser entendido cuando entabla un diálogo. En su crítica devastadora, Habermas se basó sobre todo en este argumento de la autocontradicción. Pero la hermenéutica puede acercarse a la posición de Derrida en este punto con cierta simpatía" (49), pues comparte la afirmación que "ninguna palabra o signo puede tomarse como la presencia definitiva de un sentido" (50). Participación en la verdad y no posesión de esta, apertura a un diálogo que nunca se cierra, testifican la imposibilidad de dar con un sentido objetivado tal como podría sugerirlo la metafísica de la presencia y la filosofía clásica del lenguaje. Cada palabra o signo "es simplemente señal, différance, si se quiere, o el diferir hacia algo otro que solo se puede indecir. El lenguaje vive de esta imposibilidad de satisfacer esta

(45) Ibíd., 161.

(46) Ibíd., 165. "Frente a la hermenéutica, que es el último intento de querer oír el absoluto de la ontoteología, la gramatología significa una errancia sin fin, ella nos aleja para siempre del Viernes Santo especulativo para llevar el pensamiento a la diseminación, a la pulverización del mundo, al Miércoles de Cenizas" (Ibíd., 167)

(47) Los textos del encuentro y otros sobre el tema en Antonio Gómez Ramos, Diálogo y deconstrucción. Los límites del ecuentro entre Gadamer y Derrida, U.A.M., Madrid, 1998.

(48) Jean Grondin, Introducción a la hermenéutica filosófica, Herder, Barcelona, 1999, 194.

(49) Ibíd., 195.

(50) Ibíd. 
aspiración, de la capacidad de soportar la différance entre la palabra y lo que se quiere decir" (51). Pero lo que es fatal es sostener que esa aspiración no existe para conformarse así con Derrida con la idea de que "los signos siempre remiten los unos a los otros sin dirección y sin querer decir jamás algo que se pueda verificar, o sea, sin vouloir dire alguno" (52).

Este querer decir (que implica que todo discurso tiene una referencia) que se articula en algo que es dicho (todo discurso tiene una estructura y una significación), puede ser abordado desde una teoría del discurso y filosóficamente reflexionado desde una teoría de la interpretación. A esa reflexión y teoría ha contribuido nuestro autor, y en opinión de algunos "pone en jaque a la diseminación sin fin ni comienzo que gustan proclamar hoy día algunos discípulos radicales de Heidegger y de Nietzsche, magnificando - por desesperar del sentido- el esteticismo de las palabras sin discurso o la alegría bruta de los signos sin presencia por que sin posición" (53). Sea lo que fuere, lo que sí nos parece digno de atención en que en el seno de la tradición hermenéutica, Ricoeur implica "una diferencia que hace la diferencia" (54) en la capacidad de acoger y responder los cuestionamientos críticos y deconstructivos.

b) La diferencia de Ricoeur (55). Más allá de toda la diferencia que Ricoeur puede aportar a su tradición, sabedores de que ha estimado que la filosofía debe jugar un rol de árbitro en el conflicto entre interpretaciones que reducen o amplifican el sentido y que piensa que hoy día no es posible recuperar el sentido sin sospechar de él, lo suyo es una apuesta por el sentido. No podemos estar más de acuerdo con A. Vigo cuando afirma el "inevitable primado metódico que ha de tener, incluso en una concepción de esta índole -se está refiriendo a la ricoeuriana-, el momento de la identificación benevolente frente al momento de la distancia crítica y la puesta en cuestión" (56). La necesidad de lograr una mediación integradora entre una hermenéutica benevolente o caritativa y una hermenéutica de la sospecha, no impide que la presuposición de sentido sea metodológicamente primaria e ineludible, pues de otro modo "la generalización de una actitud crítica de sospecha hasta

(51) Ibíd.

(52) Ibíd. Otro aporte de Grondin al asunto en "La définition derridienne de la déconstruction. Contribution a l'avenir du débat entre l'herméneutique et la déconstruction" (1997) en www/ mapageweb.umontreal.ca/grondinj/pdf/derrida-deconst.

(53) Pierre Gisel, "Paul Ricoeur ou le discours entre la parole et le langage", Revue de theologie et de philosophie 26 (1976), №2, 98-110.

(54) Parafraseamos el excelente artículo de Richard Berstein, “Cuál es la diferencia que marca una diferencia. Gadamer, Habermas y Rorty”, en Perfiles filosóficos. Ensayos a la manera pragmática, Siglo XXI, México, 1991, 72-110. Con una intensión semejante a la nuestra Berstein, sorprendido "de entrada (por) las diferencias decisivas e importantes" entre estos tres representante del pensamiento crítico, hermenéutico y de la deconstrucción (mientras Habermas puede ser considerado el último de los grandes racionalistas, Rorty se mofa de esta "otra variante del desacreditado proyecto fundacional de la filosofía moderna", y ambos disparan contra Gadamer, por sus velados esfuerzos por reintroducir la ontoteología), procura mostrar que aun cuando ellas tienen importancia, no pocas veces son "diferencias de énfasis" que se ven distintas cuando se sondean en profundidad (R. Berstein, art. cit., 74-75).

(55) Cf. Leonard Lawlor, Imagination and Chance. The difference between the thought of Ricoeur and Derrida, State University of New York Press, Albano, 1992. Si hacemos caso a este autor al hablar de Ricoeur debemos usar la noción de 'distanciación', dejando la de 'diferencia' reservada a Derrida.

(56) A. Vigo, art. cit., 20. 
el punto de poner radicalmente en duda toda presuposición de sentido, coherencia y racionalidad (interna) tiene necesariamente, según esto, el carácter de una suerte de profecía autocumplida, en la medida en que termina por impedir el hallazgo de genuino sentido y bloquea de antemano todo posible acceso a él" (57). Supuesta esta primacía y apuesta por el sentido, estimamos que la reflexión ricoeuriana posibilita una mejor mediación de los gestos filosóficos de base, mencionados más arriba: el gesto hermenéutico del humilde reconocimiento de las condiciones históricas a las que estamos sometidos y el gesto crítico, gesto fiero de desafío dirigido contra las distorsiones de la comunicación humana (58).

Una consecuencia particular de esta primacía, en relación a las propuestas de la deconstrucción, es la posición de Ricoeur respecto del cuestionamiento radical de toda la historia de la filosofía como metafísica de la presencia a ser superada. Una posición que nos habla de la relación de la filosofía con su propia historia. Una postura que se vuelve polémica frente a quienes solo ven en dicho pasado una ocasión para denigrarlo. "Mi empresa podría ser llamada posmoderna, si el cualificativo pudiera aplicarse a la reconstrucción y no (o no solamente) a la deconstrucción” (59).

Lejos de aquellos que se esmeran en poner una lápida condenatoria sobre la historia de la filosofía, Ricoeur cree, por el contrario, que las filosofías del pasado permanecen "abiertas a reinterpretaciones y reapropiaciones" (60). Ello en virtud de un potencial de sentido dejado sin empleo, temáticas que han permanecido secundarias, que no han sido agotadas, "por el proceso mismo de sistematización y de escolarización al cual debemos los grandes cuerpos doctrinales que identificamos comúnmente por sus eximios representantes: Platón, Aristóteles, Descartes, Spinoza, Leibniz, etc." (61).

Porque cree en el carácter inagotable de las filosofías del pasado, nos confiesa que se siente extraño frente al tema heideggeriano del fin de la metafísica. Le parece que hay una suerte de reducción, que califica de violenta, "de todo el campo filosófico a una única temática que sería la temática substancialista o la temática de la presencia. La historia de la filosofía me parece infinitamente más rica" (62).

Ricoeur estima que la idea de desconstrucción es sobre todo fecunda frente al lenguaje de la escuela -de cualquier escolástica- cuando la fecundidad de un sistema ha sido congelada. Por su parte prefiere reactivar temas inexplorados o que han permanecido secundarios, como por ejemplo aquel de la polisemia del ser del propio Aristóteles: "el substancialismo no ha agotado la ontología, ya que tenemos al menos la posibilidad de pensar el ser en términos de acto, de acción, de actuar, de padecer" (63).

(57) Ibíd., 19

(58) Cf. "Herméneutique et critique des idéologies" (1973), Du Texte a l'action, 333; 362.

(59) P. Ricoeur/A. La Coque, Penser la Bible, Paris, 1998, 163.

(60) P. Ricoeur, Soi-même comme un autre, Paris, Seuil, 1990, 346-347.

(61) Ibíd., 346.

(62) "De la volonté à l'acte", art. cit., 22.

(63) Ibíd., 22. Al hacerlo así, y preguntarse por la acción humana desde su temprana Philosophie de la volonté hasta su tardía Soi-même comme un autre, emergen y se reengendran aspectos novedosos de la metafísica, tales como la idea de conatus en Spinoza, o la filosofía de las pasiones en Hobbes, o la de los poderes en Schelling. Autorizándose de estos recursos de las ontologías del pasado, puede la hermenéutica tratar el actuar humano como un modo de ser fundamental. Cf. ibíd., 17-36. 
La metafísica no está cerrada sino inexplorada. Ella debe ser 'revisitada' (64). "Si no se pudieran despertar, liberar estos recursos que los grandes sistemas del pasado tienden a ahogar y a enmascarar, ninguna innovación sería posible, y el pensamiento en el presente no tendría más elección que entre la repetición y la errancia" (65). Sin la dialéctica entre tradición e innovación, desarrollada en Temps et récit, esta posición de principio respecto de las relaciones entre la filosofía que se hace y la historia de la filosofía no sería posible (66).

Ricouer estima, además, que la tendencia a rechazar el pasado de la filosofía dice relación con la actitud que se tiene respecto del presente. Sospecha que la filosofía que dice que el pasado se encuentra agotado, encubre un presente que sí lo está, porque ha dejado de tener contacto con las ciencias de ese presente. Buen filósofo es el que tiene al menos competencia en un dominio científico (67). "Creo que la filosofía debe tener un pie fuera de la filosofía. Si se cesa este diálogo con las ciencias, se produce entonces una filosofía de la filosofía que es repetitiva de ella misma, y toma conciencia por lo mismo de su vanidad" (68). De ello dan testimonio los conocimientos de matemáticas de Platón, o de álgebra de Descartes, o de todas las ciencias de su época de Kant. "Es probablemente a partir de Hegel -y más seguramente con Nietzsche y Heidegger- que el debate de la filosofía con las ciencias ha sido subordinado a un debate de la filosofía con su propio pasado; creo que hay allí una impasse" (69).

A la teología le es relevante este punto, no solo por interés en lo que sucede a una vecina, sino porque la afecta directamente en su propio discurso. La crítica, la ruptura respecto de la metafísica clásica, los cuestionamientos a la onto-teología la tocan directamente en la medida que su propia historia ha sido hecha con estos materiales. Ricoeur mismo no es ajeno a esta crítica. Pero no es lo mismo jugar al todo o nada, creyendo que no hay más alternativa que la aceptación total o el rechazo total, que recoger de ese pasado las posibilidades para el presente, articulando tradición e innovación. Paradójicamente las sacralizaciones y las demonizaciones del pasado son hermanas. La asunción acrítica olvida la innovación; el rechazo que pretende partir de cero olvida la tradición.

Recapitulando, recordemos que Ricoeur caracteriza su tradición filosófica con tres rasgos: "ella está en la línea de una filosofía reflexiva; permanece bajo el influjo de la fenomenología husserliana; quiere ser una variante hermenéutica de esta fenomenología" (70). La filosofía reflexiva ha sido puesta en cuestión tanto por el psicoanálisis como por el estructuralismo. Ricoeur acoge esta crítica a un sujeto y una conciencia inmediata y transparente a sí misma, desplazando la reflexión abstracta hacia una reflexión concreta, mediada, histórica. El precio a pagar es el reconocimiento de un Cogito 'herido', la transformación del sujeto. La tradición hermenéuti-

(64) "Elle doit être "revisitée', comme on dit en anglais revisited" (ibíd., 22).

(65) Soi-même comme un autre, ob. cit., 347.

(66) Cf. ibíd., 346-347.

(67) Ricoeur se lo ha impuesto como tarea respecto del psicoanálisis, la lingüística, la historiografía, la teología bíblica, etc.

(68) Ricoeur, "De la volonté á l'acte", art. cit., 23.

(69) Ibíd., 23.

(70) “De l'interprétation" (1983), Du texte à l'action, ob. cit., 25. 
ca, a su vez, ha sido duramente cuestionada por los defensores del pensamiento crítico y los sostenedores de la cruzada de la deconstrucción. Ricoeur es capaz de acoger lo mejor de esos cuestionamientos y por ello se convierte en maestro de la tradición hermenéutica. El precio se paga acá por el lado de la transformación del objeto, que sometido a la crítica y a la sospecha, nos aleja tanto de la objetividad y certeza epistemológica como del relativismo que da igual validez a cualquier sentido. Pero quizás todavía falta presentar la transformación más relevante, pues la posibilidad que Ricoeur tiene de operar un desplazamiento de la filosofía reflexiva y hermenéutica se debe a que nuestro autor, como la casi totalidad de los filósofos continentales de este siglo es a la vez deudor y hereje de la fenomenología husserliana. Los desplazamientos anteriores se comprenden a la luz de este desplazamiento fundamental.

\section{EL DESPLAZAMIENTO HERMENÉUTICO DE LA FENOMENOLOGÍA: LA HEREJÍA RICOEURIANA (71)}

Los primeros trabajos de Ricoeur nos muestran a un pensador muy cercano a la fenomenología husserliana. El discípulo e interprete crítico de esta amplía escuela, que la enseña y la comenta, es también un explorador original que vinculándola al existencialismo conduce a la fenomenología hacia las tierras de la filosofía de la voluntad. Esta originalidad se verá crecientemente desafiada por la irrupción de lo otro de la fenomenología (aquello solo abordable hermenéuticamente). El descubrimiento del problema hermenéutico es quizás el mayor desplazamiento sufrido por este discípulo de Husserl. La fenomenología hermenéutica de Ricoeur ya no es una versión más de un hereje menor sino una matriz capaz de acoger una reflexión filosófica fecunda y novedosa (72).

\section{1) El giro hacia el lenguaje como la irrupción de lo otro de la fenomenología}

El desafío hermenéutico no obliga a una renuncia a su adscripción fenomenológica. La filosofía hermenéutica de Ricoeur no abandona nunca la fenomenología y por ello deviene fenomenología hermenéutica. Y no la abandona pues aquello a lo que Ricoeur no está dispuesto a renunciar es a la subjetividad. "La fenomenología ofrece una imprescindible remisión última a la subjetividad" (73). Pero se trata de

(71) El término "herejía" podría reemplazar lo que estamos intentando decir con el de "desplazamiento" y ha sido usado por el propio Ricoeur para hablar tanto de "la suma de las variaciones de Husserl mismo" a lo largo de su vida, como de "las herejías salidas de Husserl" ("Husserl" (1967), A l'école de la phénomenologie, Vrin, 1986,9) que han terminado identificándose con la filosofía continental misma. La suya -como lo decimos en estos tres apartados- es una variante hermenéutica de la tradición reflexiva y fenomenológica.

(72) Cf. Eduardo Silva, "De la fenomenología existencial a la transformación hermenéutica de la fenomenología. Paul Ricoeur y la fenomenología”, La Fenomenología y sus herejías, María José Lopez y José Santos (compiladores), Departamento de filosofía y humanidades, Universidad Alberto Hurtado, Santiago, 2005, 211-248.

(73) Pintor Ramos, "Paul Ricoeur y la fenomenología", Paul Ricoeur: los caminos de la interpretación, Anthropos, Barcelona, 1991, 101. 
una subjetividad transformada por lo otro de la fenomenología. Lo otro es todo aquello que no puede ser abordado por el lenguaje directo, todo aquello que no puede ser reducido a puro sentido, todo lo que no resulta transparente, todo lo opaco. Lo otro ya comenzó a aparecer al abordar el campo de la voluntad en vez del de la percepción. La opacidad ya aparece en el yo puedo del yo quiero, en el análisis del mover y de lo involuntario (en sus formas de carácter, inconsciente y vida), en la consideración del cuerpo. Lo otro se hizo todavía más manifiesto, después de Voluntario e involuntario, en L'Homme Faillible, con el tema de la fragilidad y la falibilidad. Una opacidad que será creciente en la obra de Ricoeur, y dará, como él mismo lo reconoce, un carácter cada vez más aporético a sus investigaciones (74). Opacidad que al buscar ser vencida pide el recurso a la mediación del lenguaje para abordar indirectamente lo que no se deja tomar directamente con la fenomenología. Este abordaje indirecto de los fenómenos es lo que se hará presente con fuerza creciente. Camino indirecto por medio del lenguaje, por la mediación de un universo de signos que siempre pide ser interpretado.

Fue el enfrentarse con el problema del lenguaje lo que hace explotar el proyecto de fenomenología eidética que desarrolla en Le volontaire et l'involontaire, y es el lenguaje el que transforma su fenomenología existencial (preocupada por distinguir entre finitud y culpa) en fenomenología hermenéutica. Será este mismo giro hacia el lenguaje el que lo anima a indagar en las disciplinas lingüísticas, en la semiótica, el estructuralismo. La preocupación por el lenguaje lo lleva a centrar su hermenéutica en la noción de texto. La indagación e inserción en profundidad en el lenguaje le suministrarán la maestría y el dominio necesario para sus trabajos sobre la metáfora y el relato.

Ricoeur se da cuenta relativamente pronto que es sobre el dominio del lenguaje que se agrupan todas las búsquedas filosóficas. Por lo tanto, Ricoeur en su obra sostiene un diálogo fecundo con las filosofías inspiradas en lo que se ha venido en llamar linguistic turn. Intentar articular adecuadamente la relación entre realidad y lenguaje, es un desafío y rasgo que atraviesa toda su obra:

"No es que todo sea lenguaje, como se dice a veces con exceso en concepciones en que el lenguaje ha perdido su referencia al mundo de la vida, al de la acción y al del intercambio entre las personas. Pero si bien no todo es lenguaje, nada en la experiencia accede al sentido, sino con la condición de ser llevado al lenguaje. La expresión: 'llevar la experiencia al lenguaje' invita a considerar al hombre hablante, si no como equivalente del hombre en sentido estricto, sí al menos como la condición primera de ser hombre. Incluso si, en un instante, nos encamináramos a hacer de la categoría del obrar la categoría más notable de la condición personal, el obrar propiamente humano se distingue del comportamiento animal, y con más motivo del movimiento físico, en que este debe ser dicho, es decir, llevado al lenguaje, con el fin de ser significativo" (75).

Esta filosofía del lenguaje preside y da la perspectiva basal de cada uno de los hitos fundamentales de su itinerario. Una semántica del mal en su Symbolique du

(74) Cf. "Respuesta a Pintor Ramos" (1991), en ob. cit., 107-111.

(75) “Approches de la personne" (1990), Lectures 2, 209. La traducción al castellano la tomamos de "Aproximaciones a la persona", Amor y justicia, Madrid, Caparrós Editores, 1993, 111-112. 
mal (1960), una semántica del deseo en De l'interprétation, su ensayo sobre Freud (1965), una teoría semántica del símbolo en La métaphore vive (1975), una semántica de la historia o del tiempo en Temps et récit (1983-1985), una retoma de todas estas estructuras lingüísticas, prácticas, narrativas, éticas para abordar nuevamente el sujeto en Soi-meme comme un autre (1990).

Un camino de interpretaciones que permita desentrañar "el discernimiento de un sentido oculto en un sentido aparente" (76). Este mismo esfuerzo por desentrañar el doble sentido nos muestra que la opacidad esta allí en lo patente de todo lo latente. Opacidad tanto en la ambivalencia del lenguaje simbólico como en el conflicto de las interpretaciones con la irrupción de los maestros de la sospecha, y entre ellos el psicoanálisis (su energética pulsional, como lo hemos visto, no puede ser más opuesta a la pretensión de transparencia de la fenomenología). Opacidad de un lenguaje que se interpreta desde las claves de la semiótica y del estructuralismo (donde no existe ni sujeto ni sentido, y menos aún referencia) (77).

Todos estos cuestionamientos desafían a un fenomenólogo que ve que se pone en cuestión uno de los presupuestos fundamentales de la fenomenología: la transparencia de la conciencia a sí misma. La subjetividad ya no es la conciencia traslúcida y transparente a sí misma sino una filosofía de la subjetividad desgarrada. Esta purificación de la fenomenología es justamente en lo que consiste el injerto de la hermenéutica en el método fenomenológico.

\section{2) El injerto de la hermenéutica en el método fenomenológico}

Hemos recordado que Ricoeur caracteriza su pensamiento en relación a la tradición reflexiva, a la fenomenológica y a la hermenéutica. Hijo de Descartes, discípulo de Husserl, maestro de la tradición hermenéutica. ¿Por qué este heredero de la filosofía reflexiva, cuyo precedente inmediato es Jean Nabert, y de la fenomenología que le suministra el método de su primera obra se convierte en hermeneuta?

Frente a la transparencia de la conciencia a sí misma, pretendida tanto por la filosofía reflexiva como por la fenomenología, la hermenéutica aporta el reconocimiento de la opacidad del sujeto. La hermenéutica es el medio de superación de dos imposibles, de dos encajonamientos a los que lleva respectivamente un Cogito transparente a sí mismo y una conciencia inmediata. La pretensión de una aprehensión directa e inmediata del sentido, es reemplazada por una fenomenología hermenéutica en la que el significado de la existencia es abordado indirectamente (78).

Cabe entonces la pregunta inversa. ¿Por qué este hermeneuta no abandona totalmente la tradición cartesiana y fenomenológica, y sigue manifestándose tributario de ella? Para Ricoeur, la crisis del sujeto en la filosofía contemporánea continental no es razón para deshacerse de la idea de un sujeto que es responsable de sus

(76) "La question du sujet: le défi de la sémiologie" (1969), CI, 260.

(77) Una nueva "hermenéutica del yo soy" (III) capaz de superar las dificultades de la filosofía del sujeto, debe integrar "el cuestionamiento del psicoanálisis" (I) y "el cuestionamiento del estructuralismo" (II). Son los tres acápites del artículo recién reseñado, "La question du sujet: le défi de la sémiologie" y la puesta en cuestión de la hermenéutica que presentamos en la primera parte de este artículo.

(78) Cf. "The Creativity of Language" (1984), 22. 
palabras y de sus obras. "Prescindir de la clásica noción de sujeto como un Cogito transparente no significa que tengamos que prescindir de toda forma de subjetividad. Mi filosofía hermenéutica ha intentado demostrar la existencia de una subjetividad opaca que se expresa a sí misma a través del rodeo de incontables mediaciones -signos, símbolos, textos y la praxis humana misma-" (79). La idea de subjetividad, como un problema permanente que da coherencia a toda su obra, no teme ser sometida al fuego cruzado de Nietzsche y Heidegger, de una parte, y de la semiótica, del estructuralismo, del psicoanálisis y de la crítica de las ideologías, de otra (80). La crítica del Cogito se convierte en camino de una reconquista permanente de la cuestión del sujeto.

Ricoeur vuelve a la temática del sujeto, advertido por todas sus indagaciones hermenéuticas de evitar las tentaciones idealistas y subjetivistas que han acosado a la filosofía reflexiva moderna. Al retomar la cuestión del sujeto, bajo la forma de una "hermenéutica del sí mismo", debe abrirse paso entre el "sujeto ensalzado" de Descartes, y el "sujeto humillado" de Hume y Nietzsche (81); ni el Cogito que se funda a sí mismo, ni el anti-Cogito. Abandonar la ambición fundacional atribuida al Cogito no lo induce a sumarse a sus sepultureros que lo declaran definitivamente quebrado (brisé). Más bien emprende un camino antropológico más provechoso, una suerte de tercera vía, que con el nombre de hermenéutica del sí intenta dar sentido a la idea y a la expresión de un Cogito herido (blessé) esbozado en sus obras anteriores. Su hermenéutica del sí mismo es una indagación, que somete a todas las mediaciones del lenguaje, de la acción, de la narración y de la ética, a un sí que será sucesivamente llamado "locutor, agente, persona de narración, sujeto de imputación moral, etc." (82). Es la testificación de sí a todos los niveles: lingüístico, práxico, narrativo, y prescriptivo.

Podríamos decir que Ricoeur es una respuesta al fracaso de la filosofía moderna, sea como filosofía del sujeto o como filosofía de la conciencia, en la versión que cada una tiene tanto en Descartes como en Husserl. Se trata del fracaso de un sujeto que se constituye a sí mismo, de un sujeto transparente a sí, de un sujeto abstracto. De una filosofía sin presupuesto, de una reflexión abstracta. Es una respuesta también a la pretensión hegeliana de un saber absoluto que en la posesión de su certeza deja de caminar en busca de nuevas interpretaciones abiertas y provisorias. Frente a los muchos modos de idealización de un sujeto cognoscente que pretende erigirse en medida de la objetividad, Ricoeur une su reflexión a los esfuerzos heideggerianos

(79) Ibíd., 32. Símbolos, textos y acción humana son hitos en una marcha que le hizo pasar del problema del doble sentido de los símbolos al carácter paradigmático de los textos. De lo que los textos nos hablan es de la acción humana. Las fábulas imitan la acción, nos ha dicho Aristóteles. Lo que hace interesantes a los textos es su capacidad de dar figura al campo práctico donde los hombres actúan y padecen. Hermenéutica de los símbolos, hermenéutica de los textos y hermenéutica del sujeto son así los hitos de un largo itinerario.

(80) Cf. "Preface" a D. Jervolino, Il Cogito e l'ermeneutica. La questione del soggetto in Ricoeur (1984), 7.

(81) "Herméneutique du soi"; "sujet exalté”; "sujet humilié”, son expresiones que están tomadas de la apretada y magistral síntesis que nos ofrece el prefacio a Soi-même comme un autre. Corresponden a cada uno de los tres capítulos del prefacio: "Le Cogito se pose"; "Le Cogito brisé"; "Vers une herméneutique du soi".

(82) P. Ricoeur Soi-même comme un autre, ob. cit., 18. 
por resituar ontológicamente a este ser capaz de comprender el ser (83). Pero una vez más será el camino largo de todas las mediaciones lo que explica su prudencia al tratar de apropiarse la filosofía ontológica fundamental de Heidegger. Ricoeur opondrá a la vía corta de la analítica del Dasein, a lo que pudiéramos denominar su apuro ontológico, la vía larga jalonada por los análisis del lenguaje (84). Frente al modo heideggeriano, Ricoeur nos ofrece otro modo de fundar la hermenéutica en la fenomenología.

En definitiva, la filosofía hermenéutica es una filosofía que asume todas las exigencias de un largo rodeo, que renuncia al sueño de una mediación total, al término de la cual la reflexión se igualaría de nuevo a la intuición intelectual en la transparencia a sí de un sujeto absoluto (85). Una filosofía hermenéutica que quiere ser un aporte a la reflexión filosófica evitando las tentaciones que la acosan.

Por un lado, el injerto del problema hermenéutico en el método fenomenológico, el camino largo a través de todas las mediaciones, no lo hace abandonar ni la filosofía reflexiva, ni la calificación de fenomenología a su intento hermenéutico. Su crítica a la filosofía moderna no implica su abandono, por una supuesta superación por delante.

Por otro lado, esta transformación cualitativa de la conciencia reflexiva, este quebrar el recinto cerrado y encantado de la conciencia del yo, esta afirmación que "el Cogito está en el interior del ser -y no al revés-", esta "segunda revolución copernicana" (86) no olvida lo que es fruto adquirido de la primera. La revolución cartesiana descubre que la originalidad de la conciencia por relación a toda naturaleza pensada objetivamente, es tal, que ninguna cosmología puede englobar más esta conciencia. Un planteo hermenéutico que haga reventar los límites de la subjetividad, no olvida que esta ya hizo reventar los límites de la objetividad natural. Su crítica a la filosofía moderna no se tienta con una imposible vuelta atrás.

Su crítica a la filosofía moderna no es sino la recepción honesta de las críticas a su propio empeño filosófico. En su respuesta, que a la vez que constata los límites de la modernidad no reniega de sus adquiridos, podemos recapitular el camino que hemos recorrido en estos tres apartados. La filosofía de Ricoeur se ha visto afectada, y en definitiva desplazada, tanto por la puesta en cuestión de la tradición reflexiva por parte del psicoanálisis y el estructuralismo, como por los cuestionamientos a la tradición hermenéutica por parte de la teoría crítica y de la deconstrucción. Desplazamientos en la filosofía reflexiva y hermenéutica de Ricoeur que tienen directa relación con el hecho de que su matriz filosófica consiste en un desplazamiento de la fenomenología por el impacto que en ella tiene la hermenéutica. Lo suyo es un desplazamiento hermenéutico de la tradición fenomenológica. Un pensamiento que no se enorgullece de permanecer fijo, que no retiene ávidamente el ser siempre igual a sí mismo, sino por el contrario de ser afectado y en definitiva transformado por sus detractores, es un pensamiento que se ha originado en los desplazamientos provocados por los giros y los injertos que hemos descrito. La apertura que manifiesta a las

(83) Cf. "La tâche de l'herméneutique: en venant de Schleiermacher et de Dilthey" (1975), TA, 88-95.

(84) Cf. "Existence et herméneutique" (1965), CI, 10.

(85) Cf. "The Creativity of Language" (1984), 32.

(86) Cf. Le Volontaire et l'Involuntaire, Aubier, 1950, 35; La Symbolique der mal, Aubier, 1960487. 
perspectivas y razones de los otros, de los de fuera, tiene su origen en la apertura que implica una filosofía capaz de integrar a la tradición fenomenológica algo que parece tan incompatible como el problema del lenguaje y de la hermenéutica.

Esta disposición a conjugar lo que parece contradictorio, a integrar las polaridades aparentemente excluyentes, se repite a lo largo de todo su itinerario: en la filosofía de la voluntad intenta pensar juntos lo que se resiste a ser vinculado: lo voluntario y lo involuntario (la libertad y la naturaleza), la finitud y la culpabilidad (el mal padecido y el mal cometido), lo eidético fenomenológico y el lenguaje de la confesión y de los símbolos (la fenomenología y la hermenéutica); en el conflicto de las interpretaciones -lo hemos dicho- aquellas que reducen el sentido con aquellas que lo amplifican, lo arqueológico con lo teleológico, la pulsión energética con el discurso y las simbolizaciones; en sus estudios de la metáfora y la narración, la impertinencia semántica de reunir campos semánticos incompatibles o la síntesis de lo heterogéneo al conjugar acontecimientos y narraciones en una trama, de reunir relatos históricos con relatos de ficción, de vincular el sentido con la referencia, lo epistemológico con lo ontológico, la configuración con la refiguración, el texto con el lector; en su hermenéutica del sí mismo, un sujeto que a la vez habla, actúa, narra, es responsable, e incluso es llamado, y que pide por tanto aproximaciones lingüísticas, prácticas, narrativas, éticas y religiosas para ser abordado. El mismo principio de pensar junto lo que parece incompatible y evitar las dicotomías simplificadoras y excluyentes es el que anima sus estudios más recientes sobre la memoria, el reconocimiento y su redefinición de la hermenéutica como traducción (87).

Esta integración de fenomenología y hermenéutica tiene como fruto una teoría hermenéutica cuyo paradigma será la noción de texto. En ella juega un rol central la noción de distancia, aparentemente tan incompatible con una tradición que privilegia la pertenencia, la continuidad, la tradición. La hermenéutica de la distanciación será uno de los aportes más fecundos de este pensador al esfuerzo interpretativo que por esta vía privilegiará 'la actualización del texto en el acto de lectura'. Partiremos presentando por medio de tres aspectos que significa esta puesta en relación del mundo del texto con el mundo del lector: dialéctica entre la comprensión y la explicación, entre el acontecimiento y el sentido, entre el texto y el lector. Solo así estaremos en condiciones de dar un último paso, en el próximo apartado, el quinto y final, para sacar las consecuencias de todos estos desplazamientos: la pérdida que significa que el texto desvinculado de su autor, quede huérfano de padre, se compensa con los vínculos que establece con cualquiera lector que ahora lo adopta y se lo apropia. La pregunta recae entonces ahora sobre el problema de la validez de las diversas y plurales interpretaciones que ahora se disputan el texto. Creemos que Ricoeur contribuye a esbozar una vía media, que evita tanto las tentaciones de un sentido único (original, objetivo, perenne) como las de un sentido infinito (abierto, subjetivo, indeterminado).

(87) La Mémoire, l'histoire, l'oubli, Seuil, Paris, 2000; Parcours de la reconnaissance, Stock, 2004; Sur la traduction, Bayard, 2004. 


\section{ACTUALIZACIÓN DEL TEXTO EN EL ACTO DE LECTURA}

Las nociones centrales en Gadamer de pertenencia y de conciencia histórica, llevan a este a una revalidación de la tradición, de la autoridad y del prejuicio. Aunque esto se haga desde la riqueza heideggeriana, la hermenéutica de las tradiciones, como antes la hermenéutica romántica, parece ligada a todo lo que hace figura de restauración, y la vuelve blanco fácil del pensamiento crítico (88). Su rechazo a la distancia que imponen las ciencias, distancia que considera un presupuesto alienante, hace que verdad y método parecen seguir confrontados como alternativas que se excluyen. La antítesis entre hermenéutica y epistemología, heredada de Heidegger, no lograría ser suficientemente atenuada (89).

El punto de partida de Ricoeur es el intento por superar la antinomia entre distanciación alienante y pertenencia a la que Gadamer ha conducido la reflexión: “Cómo es posible introducir una instancia crítica cualquiera en una conciencia de pertenencia expresamente definida por el rechazo de la distanciación?" (90). La problemática del texto aparece como el medio de escapar a la alternativa y reintroducir una noción positiva, productiva de la distanciación: el texto "es el paradigma de la distanciación en la comunicación" (91). El texto "revela un carácter fundamental de la historicidad misma de la experiencia humana, a saber, que ella es una comunicación en y por la distancia” (92).

De esta hermenéutica de Ricoeur basada en la noción de texto nos detendremos en tres aspectos que nos parecen claves: en la primacía que tiene en el problema hermenéutico la comprensión por sobre los métodos explicativos, en el nacimiento del problema hermenéutico en la dialéctica del acontecimiento y de la significación (que es el primer rasgo de distanciación) y en el rol de la lectura y del lector en la interpretación del mundo del texto. Tres aspectos que nos hablan de lo mismo: la interpretación es, fundamentalmente, un esfuerzo por comprender las nuevas posibilidades que el texto abre y, subsidiariamente, la explicación histórica o estructural del texto; cada interpretación es un nuevo acontecimiento de lectura que intenta desentrañar la significación de un texto; la interpretación es este encuentro entre el mundo del texto y el mundo del lector. Tres modos de decir que la interpretación es la actualización del mundo que el texto despliega en el acto de lectura.

(88) Así lo hemos visto con las aprensiones de Habermas frente a Gadamer. Aun cuando ellas no sean lo suficientemente justas, y aun cuando Gadamer ha sido capaz de recoger y acoger muchas de las observaciones, sus detractores no dejan de temer el riesgo conservador.

(89) Maurizio Ferraris en su Historia de la hermenéutica (Siglo XXI, México, 2002), al tiempo que reconoce su deuda "de la monumental reconstrucción" que Gadamer ha hecho de la hermenéutica contemporánea, señala que sus dos variaciones respecto de ese modelo son la extensión más allá de la hermenéutica romántica y la atenuación de la antítesis entre hermenéutica y epistemología (Cf. ob. cit., 7). No deja de ser sintomático que la cuarta parte que lleva ese título, tiene un capítulo denominado de la hermenéutica a la epistemología" y que consiste en la presentación de Ricoeur y de Apel.

(90) P. Ricoeur, Du texte a l'action, 99.

(91) Ibíd., 102.

(92) Ibíd., 102. 


\section{1) Dialéctica entre comprensión hermenéutica y explicación metódica}

Ricoeur se ocupa de la tensión entre la búsqueda histórica y la actualización hermenéutica. El problema de fondo está en que los desarrollos de la hermenéutica filosófica tienen algo que decir respecto de un privilegio unilateral del método histórico-crítico. Una hermenéutica ya no preocupada de las intenciones del autor, ni de lo que está detrás del texto, sino de lo que está en él y de lo que este abre, tiene mucho que aportar al arduo trabajo de interpretación exegética al que son sometidos los textos clásicos, literarios, filosóficos, bíblicos, jurídicos.

Se trata del desplazamiento provocado por la hermenéutica desde preocupaciones histórico-genéticas al texto mismo, y al mundo que este abre. Pero este conflicto no es el único que debe superar quien aboga por la complementariedad de los métodos. El movimiento desde lo histórico hacia lo hermenéutico se vuelve más complejo por la irrupción del método estructural y su pretensión de subordinar todo lo diacrónico a lo sincrónico. La apuesta de Ricoeur consiste en transformar esta mayor complejidad, que para muchos implica una polaridad excluyente, en una mediación, que permita un tránsito desde lo histórico a una hermenéutica muy atenta a las estructuras del texto.

Ricoeur sostiene que el análisis estructural puede ser conectado con una interpretación existencial, a condición de que sea desconectado de la ideología estructuralista (93). Así se transforma en un método que no niega la hermenéutica al establecer una vía alternativa, sino que la enriquece al ser una etapa intermedia y necesaria (94).

Por ello para Ricoeur la pareja estructura-génesis reenvía, a su vez, al tercer polo que tiene la primacía: la interpretación. Para Ricoeur la exégesis es solo la preparación de un volver a tomar el texto por parte de un lector de hoy, que lo pone en relación con sus propios problemas. Este lector, al apropiarse el texto, vence la distancia cultural, que el análisis estructural y la construcción genética han todavía ahondado más (95). "El teólogo y el filósofo interpretan en la medida que ellos ponen en relación el texto con una problemática constituida más allá de él" (96). Vemos aflorar la relación clave en la hermenéutica ricoeuriana entre el mundo del texto y el mundo del lector (97), que abordaremos al final de este acápite.

Pero la interpretación no es solo del texto o sobre el texto; debe serlo también y, previamente, "interpretación en el texto y por el texto" (98). Solo así se evita que la interpretación haga violencia al texto, que sea "la irrupción de la subjetividad del exégeta en la objetividad del texto" (99). Interpretar es colocarnos en la dirección

(93) Cf. P. Ricoeur, "Biblical Hermeneutics", 65.

(94) Después de hacer todo el recorrido que va desde los formalistas rusos hasta los estructuralistas franceses (desde Propp hasta Barthes, pasando por Levi-Strauss y Greimas), Ricoeur nos plantea su posición en un apartado que titula: 'Estructuralismo: ¿un estadio intermedio o una vía alternativa?'. Cf. ibíd., 63-73.

(95) Cf. ibíd., 80.

(96) Ibíd., 80.

(97) Es título de uno de los capítulos de la cuarta parte de Temps et récit.

(98) Ibíd., 80.

(99) Ibíd., 83. 
del texto, y para ello requerimos los métodos anteriores, pues "el juego de la estructura y de la génesis revela alguna cosa de lo que se puede llamar la intención del texto" (100).

Pero este juego se interrumpe cuando los métodos históricos pretenden que la interpretación es trasladarnos a las cosas tal como sucedieron. También cuando los métodos semióticos pretenden lo que llama la hipóstasis literaria del texto. Dicha hipóstasis del texto en sí, es principio metódico de no pocos lingüistas y se ha visto favorecida por la ideología estructuralista -recién mencionada- que niega que los textos tengan referencia, en virtud de que solo tienen sentido. Los análisis exegéticos -históricos o estructurales- si no están al servicio de la interpretación del texto, si pretenden la primacía en vez de considerarse disciplinas auxiliares, pueden volverse aburridos en la medida que acaban con el juego (101).

Lo interesante está en la vinculación que establece entre el sincronismo estructuralista y el diacronismo de los métodos genéticos: ambos pueden olvidar que el texto es un eslabón en una cadena de comunicación que, si lleva al lenguaje una experiencia, solo termina cuando el lenguaje es llevado nuevamente a la experiencia. Y eso solo ocurre en la actualización que produce la lectura. Si no "el texto no es más que un artefacto del método crítico" (102). Será artefacto, no solo cuando se lo coloca en serie con otros artefactos, en el sincronismo de la intertextualidad, sino también cuando se lo remite a otros textos históricamente. De esta práctica hay testimonios abundantes en el criticismo bíblico: "la antigua Quellenforschung practicaba ya ese juego de remisión de texto a texto en una filiación genética" (103). Se trata del mismo proceso, "abstraer un texto de la cadena comunicativa, referirlo a otro texto igualmente abstraído y hacer de esos textos un todo de series estructurales o genéticas" (104), y de la misma ilusión, "creer que se ha comprendido mejor un texto cuando se conoce otro texto de donde procede por adopción o por cita" (105).

El pecado compartido es olvidar la función fundamental del discurso que consiste en decir algo a alguien sobre algo... Los textos refieren a un mundo, que es el mundo del texto. Tal es el objeto de la hermenéutica. La cosa del texto "no está ni

(100) Ibíd., 84. Ricoeur se reconoce deudor de Paul Beauchamp y en este punto, como en otros comparte sus juicios: "La interacción de estructura y génesis revela algo que podemos llamar la intención del texto. 'Toda intención -dice Beauchamp- cuando se ve que tiene fuerza, está organizando... Es la intención que despliega una genética inmanente en la estructura'. Este importante texto de nuestro exégeta transmite bien la interacción de estructura, génesis e intención. Es la tarea de una teoría de la interpretación pormenorizada preservar esta interacción y magnificarla" ("Sur l'exégése de Genese 1, 1-2, 4a" (1971), en Exégése et herméneutique. Editado por X. LeonDufour, Paris, Seuil, 1971, 67-84).

(101) "La teoría de la interpretación de Paul Ricoeur relativiza las prácticas exegéticas. Por un lado la descontextualización del texto respecto de su autor, su situación y destinatarios originales relativiza el método histórico-crítico. Por otra parte aceptará la exégesis estructural, pero solo porque nos otorga una ayuda para leer mejor la estructura narrativa" (Van Den Hengel, J. W., The Home of Meaning. The Hermeneutics of the Subject of Paul Ricoeur., U. Nijmegen [Washington], University Press of America, 1982, 230).

(102) P. Ricoeur, Lectures 3, 284

(103) Ibid., 285

(104) Ibid.

(105) Ibíd. 
detrás del texto como el autor presumido, ni en el texto como su estructura, sino desplegado ante él" (106). Es esta concepción hermenéutica la que tendrá significativas consecuencias para la teología (107).

Resumamos, con otras palabras. Este privilegio del presente, de la apropiación, de la lectura, de la comprensión en la teoría de la interpretación, implica que tanto los métodos diacrónicos como los métodos sincrónicos se ponen al servicio de la interpretación. La explicación al servicio de la comprensión: "explicar más para comprender mejor" como repite incansablemente Ricoeur. En el criticismo bíblico, por el contrario, se ha privilegiado lo inverso, pues la insistencia y la investigación han estado centradas más sobre las sucesivas etapas del texto y sobre la "determinación de la situación original del texto que en un análisis de su forma literaria final y su relación con la situación contemporánea" (108). En la hermenéutica contemporánea, en cambio, hay una primacía, un privilegio del estado actual del texto abierto a sus intérpretes, que permite escapar tanto a la tentación diacrónica como a la tentación sincrónica. Lo sintetizamos en tres asertos:

- No privilegiar o detenerse en la diacronía es no buscar 'detrás del texto'. Lo fundamental en la interpretación no está ni en las intenciones del autor, ni en el contexto histórico-social, ni en los primeros destinatarios.

- No privilegiar o detenerse en la sincronía es no buscar 'dentro del texto'. Implica hacer uso de los métodos estructuralistas rechazando la ideología estructuralista que niega que el texto tenga un afuera, que tenga referencia. No aceptar la clausura, del texto, su epoje.

- Ni detrás, ni dentro, sino buscar delante del texto, frente a él. Delante del texto está el lector, está el intérprete. Intérprete con su mundo, con su horizonte, con su pre-comprensión. Se trata de buscar lo que el texto abre, las posibilidades que ofrece.

Notemos que buscar detrás del texto el sentido original se asemeja al deseo de una objetividad, a un sentido fijo, invariable, verdadero, único, válido para todos los tiempos. Notemos que encontrar en el texto mismo, desconectado de toda referencia a un mundo, es la apuesta estructuralista, que en manos de los posestructuralistas descubren que no hay sentido, sino solo signos que remiten a otros signos. La hermenéutica quiere escapar tanto al objetivismo, de lo primero, como al relativismo de lo segundo.

(106) Ibíd., 286.

(107) "Para reconocer el carácter creador de toda interpretación, es necesario haber desmitificado la ilusión de un sentido que estaría detrás del texto (en la conciencia de su autor, en la reconstitución de su contexto sociohistórico o en su primera recepción) o aun en el texto mismo. El sentido está mucho más en el buscar en este "delante" que es el punto de reencuentro del horizonte del texto y de nuestro propio horizonte de comprensión" (Geffre, Le christianisme au risque de l'interprétation, 10).

(108) Jeanne Evans, Paul Ricoeur's Hermeneutics of de Imagination, Peter Lang, New York, $1995,4$. 


\section{2) La dialéctica acontecimiento y sentido (109)}

Si la noción de texto posee un carácter paradigmático, y aparece como el aporte de Ricoeur al problema hermenéutico, debemos partir por atender a la dialéctica del acontecimiento y de la significación, que nos es presentada como el primer rasgo de distanciación, condición de posibilidad de todo lo ulterior, lugar de nacimiento del problema hermenéutico.

Saussure nos enseñó a distinguir entre lengua y habla, y poniendo entre paréntesis el habla y su uso, se centró en los códigos y estructuras de la lengua. La teoría del discurso, tal como la desarrolla el lingüista francés Emile Benveniste, levanta el paréntesis, y se ocupa de la efectuación del lenguaje como discurso, del acontecimiento de discurso. El discurso consiste en que alguien dice algo a alguien sobre alguna cosa. El discurso es un acontecimiento cuando destacamos su realización temporal y actual, la intención del locutor, la situación, y el destinatario original. Pero el discurso es también significación cuando prevalece al suceso fugitivo del decir, lo dicho del decir; a la intención mental del locutor la significación verbal del texto mismo; a la referencia ostensiva la dimensión mundo; al destinatario original la universalidad del cualquiera que sepa leer. Estos rasgos se aprecian con más claridad cuando se pasa de lo oral a lo escrito. Es la superación del acontecimiento en la significación. La lengua no solo se efectúa, sino que también se comprende. El discurso no solo acontece sino que también significa (110). "Todo discurso se efectúa como acontecimiento, pero todo discurso es comprendido como sentido" (111).

El paso del discurso oral a la escritura hace más explícito los rasgos que señalábamos más arriba, por la triple autonomía que el texto escrito subraya. Autonomía respecto de la intención del autor que, al no estar ya más presente, abandona el texto a su propia significación. Autonomía respecto de la situación dialogal que reemplaza al destinatario original por cualquiera que lea el texto. Autonomía respecto de la situación común de los interlocutores que cede su lugar al mundo al que el texto refiere. Triple autonomía que nos muestra que la distanciación no es una alienación que introduce la metodología, sino que es "constitutiva del fenómeno del texto como escritura" (112).

"Así de cuatro maneras diferentes, el discurso llega a ser acontecimiento, y de cuatro maneras diferentes el acontecimiento se supera en el sentido: por la fijación que lo sustrae a la desaparición, por la disociación que lo sustrae a la intención mental del autor, por la apertura sobre un mundo que lo arranca a los límites de la situación de diálogo, por la universalidad de una audiencia ilimitada" (113). Gracias a todas estas formas, el sentido va más allá del acontecimiento, es trans-eventual.

(109) Seguimos muy de cerca los artículos de P. Ricoeur "Événement et sens” (1971), "Événement et sens dans le discours" (1971) y "La fonction herméneutique de la distanciation" (1975), Du texte a l'action, 101-105.

(110) Cf. "La fonction herméneutique de la distanciation", 105.

(111) "Événement et sens", 17.

(112) "La fonction herméneutique de la distanciation", 112.

(113) "Événement et sens dans le discours", 183. Hacemos uso de la traducción al castellano (manteniendo las cursivas del texto original) que se ofrece en Texto, testimonio y narración, Santiago, Ed. Andrés Bello, 1983, 104-105. 
De allí nace el proceso hermenéutico. "Si la lengua se desborda en el discurso, si en el discurso el acontecimiento se desborda en el sentido, hay que decir ahora que el sentido se desborda en un nuevo acontecimiento de discurso que es la interpretación misma” (114).

El discurso es un acontecimiento, y la lectura es un nuevo acontecimiento, y ambos están atados al texto que da el sentido. Se puede llegar a decir que la lectura es al texto, lo que el habla (el discurso) es a la lengua (115).

\section{3) La dialéctica entre el mundo del texto y el mundo del lector}

Ricoeur sostiene que la noción mundo del texto es la categoría central en su concepción hermenéutica. No pocas veces simplemente identifica su hermenéutica con este rasgo (116). Sin embargo, también nos ha dicho que con la noción del mundo del texto se ha recorrido solo la mitad del camino, pues se trata de una trascendencia en la inmanencia (117). Con el paso que va de su obra sobre la metáfora a aquella sobre la narración el recorrido se completa. Temps et récit aporta la otra mitad del camino al recurrir a la mediación de la lectura, marcando con ello la diferencia más sensible respecto de La Métaphore vive (118) y de su hermenéutica basada en la noción de texto. La modificación ha sido posible gracias al descubrimiento del rol del lector y la lectura. Cuando la lectura y el mundo del lector intervienen, el mundo del texto es recomprendido en términos de refiguración y no solo de mera referencia. Gracias a la lectura se da el paso desde una trascendencia en la inmanencia a una verdadera trascendencia.

Ricoeur nos lo dice claramente: "Es en la intersección del mundo del texto y del mundo del lector que algo sucede. La lectura se convierte en un acontecimiento, y es la capacidad de los relatos clásicos o modernos de abrir una brecha en nuestra experiencia cotidiana y así problematizarla o (...) poetizarla. Pero es necesaria esta colaboración, incluso esta amistad, entre un lector que tiene sus esperas y un texto que tiene una estructura. La dialéctica de la estructura interna y de la espera del lector contiene todo el problema de la esperanza poética" (119).

Al hablarnos de la lectura en Temps et récit, Ricoeur alude a la noción hermenéutica de aplicación, muy trabajada por Gadamer, y a la que el propio Ricoeur ha dado el nombre de apropiación (120).

Con todas estas expresiones se indica el hecho de que un texto está dirigido a alguien: a cualquiera que pueda leerlo. Un lector concreto se apropia el significado del texto. El desafío para Ricoeur será ubicar este problema del rol de la subjetividad, no en la tradición de las filosofías del Cogito y de la conciencia que hacen del sujeto la clave de toda constitución, sino en coherencia con su filosofía hermenéutica, que al privilegiar el poder de la obra para revelar un mundo, concibe un sí mismo -breve-

(114) "Événement et sens dans le discours", 183.

(115) Cf. "Événement et sens", 22.

(116) P. Ricoeur, "Nommer Dieu", Lectures 3, 304.

(117) Cf. Temps et récit III. Le temps raconté, Seuil, Paris, 1985, 230.

(118) Cf. ibíd., 230.

(119) P. Ricoeur, "Carta a H.Seweryniak (9 julio 1983)" (1983), 402.

(120) Seguimos el ensayo al que el propio Ricoeur refiere: "Appropriation" (1977). 
mente un sí (soi)-, que se amplía al aprehender lo que le es propuesto. La apropiación se ubica entonces en referencia dialéctica al concepto fundamental de distanciación.

En la hermenéutica de Ricoeur el rol que se concede al sujeto bajo los términos de aplicación, apropiación, actualización, lectura, etc., mantiene la presuposición básica de la objetividad del significado. Un fruto adquirido gracias a la influencia de la fenomenología en su hermenéutica, y que implica todo un desplazamiento respecto a la tendencia del criticismo bíblico y literario desarrollado desde el siglo XIX. Esta última privilegia las condiciones sociales de la comunidad que ha producido los textos o a la que ellos están dirigidos. Para explicar un texto es necesario comprender su espacio y su tiempo. Solo así sabremos las ideas que ellos tenían en mente. Contra esta posición, Frege y Husserl sostienen que lo que interesa en el significado "no es un contenido mental sino un objeto ideal que puede ser identificado y reidentificado, por diferentes individuos en períodos diferentes, como siendo uno y el mismo objeto" (121). Este giro desde lo histórico hacia lo lógico, con la suerte de distancia respecto del historicismo y del subjetivismo que implica, ha tenido no poca influencia en la renovación de la dialéctica entre explicación y comprensión de la que la obra de Ricoeur es testigo.

Ahora corresponde apreciar cómo la objetivación del significado es una mediación necesaria entre el escritor y el lector. Una objetivación que debe ser complementaria a la apropiación de ese significado. Se trata de hacer propio lo que era ajeno, actualizar un significado dirigido a alguien. Si en la situación dialogal es la respuesta lo que corresponde a la referencia ostensiva, en la situación hermenéutica es la apropiación lo que corresponde a la 'revelación' o 'descubrimiento' de un mundo (122).

La articulación entre apropiación y revelación es lo que permite que la apropiación sea primariamente 'dejar hacer'. Leer es una apropiación-desposesión. Implica que la renuncia es un momento fundamental de la apropiación y la distingue de cualquier forma de tomar posesión. Renuncia que se logra al enlazar la apropiación al poder revelador del texto. Al ser llevado hacia la referencia del texto el ego despoja al sí de sí. La noción de sujeto es sometida así a una crítica paralela a la que la teoría de la metáfora ejerce sobre la noción de objeto (123).

El vínculo de la apropiación a la revelación permite, paradójicamente, cumplir la intención original de la hermenéutica de Schleiermacher. "Comprender un autor mejor que lo que se comprende a sí mismo es desplegar el poder revelador implícito en su discurso, más allá del horizonte limitado de su propia situación existencial"

(121) “Appropriation", 184. En Frege se trata de la dimensión ideal de la proposición constituida por la identidad de 'sentido' en la infinita serie de sus actualizaciones mentales; en Husserl del objeto 'noemático', irreductible a los aspectos mentales de los actos mismos. "For a phenomenology 'turned towards the object', all intentional acts without exception must be described in terms of their noematic side, undestood as the 'correlate' of the correspondig noetic acts" (ibíd., 184).

(122) Cf. ibíd., 185.

(123) Es comprensible entonces, que una crítica de las ilusiones del sujeto deba ser integrada a la hermenéutica. La crítica del sujeto, que en la tradición marxista es uno de los aspectos de la teoría general de la ideología, nos advierte de la falsa conciencia y de los prejuicios vinculados a nuestra posición en las relaciones de fuerza de la sociedad, e invita a un diálogo entre hermenéutica y la teoría de la ideología desarrollada, por ejemplo, por Habermas. En la tradición freudiana la crítica de las ilusiones del sujeto favorece la purificación, en el acto de apropiación, del 'narcicismo del lector' que se encuentra a sí mismo en el texto, y facilita la renuncia del sujeto a la que nos referíamos. Cf. ibíd., 191. 
(124). Pero, sobre todo, permite refutar puntos de vista erróneos y falaces respecto de lo que es la interpretación. En primer lugar, la apropiación no implica ninguna directa congenialidad con el autor (125). En segundo lugar, la apropiación no es la primacía de la audiencia original, ni la tarea hermenéutica debe ser gobernada por esta original comprensión del texto (126). Finalmente, y es el error contra el que estamos luchando, tampoco la apropiación implica subsumir la interpretación a las capacidades finitas de comprensión del lector presente. No coloca el significado del texto bajo la dominación del sujeto que lo interpreta. Esto se puede evitar porque lo que es hecho propio es la proyección de un mundo, la proposición de un modo de ser-en-el-mundo. "La apropiación es el proceso por el cual la revelación de nuevos modos de ser $-\mathrm{O}$, si se prefiere Wittgenstein a Heidegger, nuevas 'formas de vida'dan al sujeto nuevas capacidades para conocerse a sí mismo” (127). Más que proyectarse a sí mismo, la capacidad del lector de proyectarse se ensancha al recibir un nuevo modo de ser desde el texto mismo.

La apropiación, lejos de ser una forma de subjetivismo, conlleva un momento de desposesión del ego narcisista. La autocomprensión que implica solo es posible después de seguir la flecha de sentido del texto y del esfuerzo de pensar de acuerdo con él. "Es el texto, con su universal poder de develamiento, el que da un sí al ego" (128). Se abre así una dialéctica entre el mundo del texto y el mundo del lector (129). Se trata de un "encuentro entre el conjunto de las pretensiones del texto, el

(124) Ibíd., 191.

(125) La fusión de horizontes de Gadamer no es un retorno a esta pretensión romántica, pues se trata de la convergencia del mundo-horizonte del escritor y del lector por la mediación de la idealidad del texto. Cf. ibíd., 192.

(126) "The Letters of Saint Paul are no less addressed to me than to the Romans, the Galatians, the Corinthians, etc." (ibíd., 192). No hacemos más que recordar que si el significado de un texto está abierto a cualquiera que pueda leer, puede escapar a su original audiencia como ha escapado a su situación y autor.

(127) Ibíd., 192. Por ello la 'precomprensión' heideggeriana dista mucho de ser la proyección de los prejuicios del lector en su lectura. Por lo mismo, el círculo hermenéutico de Bultman, 'creer en orden a comprender', no es proyectar la misma lectura dentro del texto leído. Cf. ibíd., 190.

(128) Ibíd., 193. Esta alusión al sí permite situar su filosofía hermenéutica en relación a la tradición reflexiva kantiana y a la tradición especulativa hegeliana. Una equidistancia a la que Ricoeur alude varias veces. Colocándose a igual distancia de ambas, no deja de aceptar sus aportes al tiempo que se opone a ellas con igual fuerza. Al vincular comprensión del significado con autocomprensión, la filosofía hermenéutica es una continuación de la filosofía reflexiva. Pero la crítica de las ilusiones del sujeto y el rodeo por los signos distancian a Ricoeur de conceder la primacía al Cogito. La subordinación de la apropiación a la manifestación lo gira más hacia una hermenéutica del yo soy que a una del yo pienso. Y, precisamente, este concepto de manifestación de un mundo lo acerca a la idea de 'autopresentación' de la verdad, tan característica de la especulación hegeliana. Pero el permanente retorno de esta autopresentación al acontecimiento de la palabra, en el cual, últimamente, la interpretación es cumplida, significa la lejanía respecto del saber absoluto. No se puede escapar ni superar el conflicto de las interpretaciones. Por ello, "between absolute knowledge and hermeneutics, it is necessary to choose" (ibíd., 193).

(129) Dialéctica a la que se consagra uno de los capítulos de Temps et Récit y que pondrá la teoría de la lectura en el corazón mismo de la empresa hermenéutica. Pero ella ya estaba presente en el recuento Du texte à l'action, cuya segunda parte está consagrada en parte al diálogo entre teoría del texto y teoría de la lectura (Cf. Roger Chartier, "Débat [autour de 1'histoire], en Paul Ricoeur, Esprit 7-8, juillet-âout 1988, 258). En Temps et Récit Ricoeur recurre a una teoría de la lectura, que es deudora por una parte de la fenomenología del acto de lectura en la cadena que remonta de Iser a Ingarten y Husserl y, por otra de una estética de la recepción pública o colectiva tomada prestada de H.R. Jauss. Prestaremos a estos autores, de la escuela de Constanza, en el acápite 5. 
horizonte que él abre, las posibilidades que él despliega, y otro horizonte, el horizonte de espera del lector" (130).

Pero esta dialéctica no nos puede hacer olvidar un rol de la lectura, que es anterior a este encuentro, que pone en relación el decir del texto y el hacer de los hombres actuantes y sufrientes. El acto de lectura está implicado en la constitución misma de lo que llamamos el sentido de un texto. Ricoeur ha distinguido estos dos roles claramente. Por un lado, "solo en la lectura el dinamismo de configuración acaba su recorrido" (131). Por otro, "es más allá de la lectura, en la acción efectiva, ilustrada por las obras recibidas, donde la configuración del texto se cambia en refiguración" (132). Ahondemos en lo primero, y en alguna de sus consecuencias, antes de referirnos brevemente a lo segundo.

Primero, la lectura, lejos de ser un complemento que podría faltar, concluye el sentido del texto. Creer que se trata de un acontecimiento extrínseco y contingente es mantener la ilusión de que el texto está estructurado en sí y por sí. "El proceso de composición, de configuración, no es completado en el texto sino en el lector" (133). La imagen de un verdadero combate del lector para construir el texto es más exacta que la que nos dan las bibliotecas llenas de libros no leídos, que si bien no refiguran nada tendrían supuestamente una configuración bien delineada. Pero Ricoeur es enfático: "sin lector que lo acompañe, no hay acto configurador que actúe en el texto; y sin lector que se lo apropie, no hay mundo desplegado delante del texto" (134).

Se libera al lector del paréntesis en el que había sido puesto junto con el autor. El texto sigue siendo huérfano de padre, esto es de su autor, pero puede llegar a ser el hijo adoptivo de la comunidad de los lectores. Es el último paso para poner fin a la ilusión del autor como creador soberano (135).

El acto de lectura actualiza el texto, lleva al acto las posibilidades semánticas de un texto que construye desde entonces en sus lecturas una significación. Al decir construcción, no estamos excluyendo las lecturas que a menudo desestabilizan el texto. Por el contrario se subraya una dialéctica entre la estructuración interna del texto y todas las actividades de desestructuración-reestructuración que hacen parte de la lectura. "Esta dialéctica hace de la obra el efecto común del autor y del lector (...). La tensión es inevitable entre las resistencias estructurales del texto (...) y los efectos de desestabilización engendrados por la lectura" (136).

Pero no conviene reducir el acto de lectura a una especie de cara a cara de un lector y de un texto. Hay también una historia de la lectura, hecha de los cambios de horizonte de las expectativas de los lectores. En cada época los lectores individuales o las comunidades de lectura, como por ejemplo las iglesias, abordan los textos con esperas determinadas. Cada época leerá diferentemente los mismos textos. "Esto hace que la historia de la lectura se incorpore de tal manera a la inteligencia de los

(130) P. Ricoeur, "Monde du texte, monde du lecteur" (1987), 99.

(131) P. Ricoeur, Temps et Récit III, 230/866.

(132) Ibíd., 230/866.

(133) P. Ricoeur, "Life in quest of narrative" (1991), 26.

(134) P. Ricoeur, Temps et Récit III, 239/875.

(135) Cf. P. Ricoeur, "Éloge de la lecture et de l'écriture" (1989), 403.

(136) P. Ricoeur, "Regards sur l'écriture" (1989), 216. 
textos que se puede decir que la significación de un texto es el fruto común de la obra que resiste a nuestra arbitrariedad y de la lectura que criba el sentido en función del horizonte finito de nuestras esperas" (137). Tales esperas son desde este punto de vista efectos culturales, que variarán en el tiempo y entre un individuo y otro (138).

De allí la imposibilidad de fijar de una vez para siempre el sentido de un texto, y la inevitabilidad que exista una pluralidad de lecturas y de interpretaciones respecto de los mismos textos. El horizonte de estos problemas está en el estatuto de la idea de verdad que no es de orden unívoco. Para escapar tanto a la tentación de creer que un texto tiene una única interpretación fija y oculta, como a la tentación inversa de no leer sino lo que se proyecta en el texto, Ricoeur nos dice que un texto es un espacio finito de interpretaciones: no hay una sola interpretación, pero tampoco un número infinito de ellas (139).

Segundo, es más allá de la lectura que el texto termina su recorrido. Acompañar la configuración del texto es solo una de la doble respuesta del lector al texto. La lectura es también mediación de la refiguración. Que sea el lector el que complete el proceso de configuración del texto es la condición que hace posible la reconfiguración de la vida por medio de la narración. Mediante la apropiación del mundo desplegado por el texto, se da tanto la comprensión del texto como la comprensión de sí mismo.

Por ello Ricoeur señala dos momentos en la dialéctica que enfrenta y liga el mundo imaginario del texto y el mundo efectivo del lector. Un momento de interrupción, de éxtasis, de pausa que somete las esperas del lector a las que el texto desarrolla. El lector se irrealiza "en la medida de la irrealidad del mundo de ficción hacia el que emigra" (140). Una experiencia de pensamiento por la cual nos ejercitamos en habitar mundos extraños a nosotros mismos (141). Un momento en el que ocupa un rol preferente la imaginación, y que Ricoeur siguiendo el tema del 'juego' en Gadamer, ha llamado 'metamorfosis del lector' (142).

Un segundo momento tiene que ver con el ser relanzado hacia la acción, con el envío. Al incorporar, consciente o inconscientemente las enseñanzas de sus lecturas a su propia visión del mundo, aumentando así la legibilidad previa, "la lectura es para él otra cosa que un lugar en el que se detiene; es un ámbito que atraviesa" (143). Al apropiarse el mundo de la obra el lector recibe una proposición de existencia, una nueva evaluación del mundo. "La lectura se convierte en una provocación para ser y obrar de otro modo" (144). Obviamente este envío no se transforma en

(137) "Éloge de la lecture et de l’écriture" (1989), 404.

(138) "Pour interprète donné, il y a effectivement une bonne interprétation, une interprétation plus plausible, étant donné ce qu'il sait, ce qu'il est, ce qu'il attend... Pour un autre, qui n'aura pas les mêmes attentes, le même horizon culturel, le point d'équilibre [entre la mejor de las expectativas y la información más íntegra] se fera ailleurs, mais il sera non moins contraignant pour lui que pour le premier" ("Monde du texte, monde du lecteur" (1987), 101).

(139) Cf. "Monde du texte, monde du lecteur", 101.

(140) P. Ricoeur, Temps et Récit III, 262/900.

(141) Cf. ibíd., 358.

(142) Cf. "Appropriation" (1977), 185-190.

(143) P. Ricoeur, Temps et Récit III, 263/900.

(144) Ibíd., 358-359/1001. 
acción sin que medie una decisión ética. Corresponderá al lector, convertido en agente iniciador de la acción, elegir entre las múltiples proposiciones éticas vehiculadas por la lectura (145).

\section{LA HERMENÉUTICA COMO UN MÁS ALLA DEL OBJETIVISMO Y EL RELATIVISMO}

Rasgo característico de la hermenéutica de Ricoeur -lo hemos señalado con insistencia- es procurar mediar polos que se presentan como excluyentes. Su interés por integrar la noción de distanciación en una tradición caracterizada por la pertenencia ("la comunicación en y a través de la distancia", nos ha dicho (146)) se manifiesta en los complementos que aporta a sus predecesores: frente a Gadamer evita prescindir de las cuestiones de método en la búsqueda de la verdad, frente a Heidegger hace un camino de vuelta desde la radicalidad ontológica hacia las consideraciones epistemológicas, frente a Dilthey intenta superar la dicotomía entre ciencias del espíritu y ciencias de la naturaleza (147). La búsqueda de una hermenéutica atenta a las cuestiones metódicas y epistemológicas para no tener que suscribir tan fácilmente las tesis de Dilthey que estima que "o bien se explica, a la manera del sabio naturalista, o bien se interpreta, a la manera del historiador" (148). En particular su enfrentamiento con el estructuralismo le hace considerar "el análisis estructural como una etapa -y una etapa necesaria- entre una interpretación ingenua y una interpretación crítica" (149), en la que la explicación de las estructuras, de las relaciones internas de dependencia que constituyen la estática del texto, sirve para interpretar, e.d., para "tomar el camino del pensamiento abierto por el texto, para ponerse en la ruta hacia el oriente del texto" (150). Con ello se corrige "una operación subjetiva de la interpretación como acto sobre el texto" por "una operación objetiva de la interpretación como acto del texto" (151). Superadas las polaridades excluyentes es "posible situar la explicación y la interpretación en un único arco hermenéutico e integrar las actitudes opuestas de la explicación y la comprensión en una concepción global de la lectura como recuperación del sentido" (152).

(145) Cf. ibíd., 359. En sus conclusiones, y a propósito de la identidad narrativa, Ricoeur nos muestra estos vínculos entre lo narrativo y lo prescriptivo, que luego desarrollará ampliamente en Soimême comme un autre. Si bien el paso a la responsabilidad ética es factor indispensable de la ipseidad y nos permite apreciar los límites de una identidad solo narrativa, la narración no está desprovista de la dimensión normativa, evaluativa, prescriptiva. Cf. ibíd., 359.

(146) Recordemos la cita completa: "el texto... es el paradigma de la distanciación en la comunicación; a este título revela un carácter fundamental de la historicidad misma de la experiencia humana, a saber que ella es una comunicación en y por la distancia" (Ricoeur, "La fonction herméneutique de la distanciation" (1975), Du texte à l'action, ob. cit., 102).

(147) Cf. Ricoeur, "La tâche de l'herméneutique: en venant de Schleiermacher et de Dilthey" (1975), ob. cit., 75-100.

(148) Ricoeur, “QQue es un texto?”(1970), ob. cit., 142.

(149) Ibíd., 155.

(150) Ibíd., 156.

(151) Ibíd., 156. Ricoeur habla incluso de la intención o el objetivo del texto.

(152) Ibíd., 155. 
Explicar más para comprender mejor; la explicación al servicio de la comprensión; explicación estructural (o genética) para favorecer lo que está en el otro extremo del arco: la apropiación. Una noción ya presente en Schleiermacher, Dilthey y Bultmann, que hace que "la interpretación de un texto se acaba en la interpretación de sí mismo de un sujeto que desde entonces se comprende mejor, se comprende de otra manera o, incluso, comienza a comprenderse" (153). En segundo lugar el término apropiación subraya la lucha contra la distancia cultural, contra el alejamiento del sentido, pues "la interpretación "acerca", "iguala", convierte en "contemporáneo y semejante", (...) hace propio lo que en principio era extraño" (154). Un tercer aspecto que la apropiación destaca es "el carácter "actual" de la interpretación: la lectura es como la ejecución de una partitura musical; ella marca la efectuación, la venida al acto, de las posibilidades semánticas del texto. Este último rasgo es el más importante porque él es la condición de los otros dos: victoria sobre la distancia cultural, fusión de la interpretación del texto y la interpretación de sí mismo (155).

Actualización del texto en el acto de lectura, apropiación, primacía del polo obra-lector por sobre el polo autor-obra es una insistencia de la filosofía hermenéutica desde Heidegger y Gadamer. La lectura de estos filósofos ha sido importante para el desarrollo en la crítica literaria de una teoría que pone los énfasis justamente en el lector y en la recepción del texto. Pero insistente también ha sido la preocupación de otros que ven en este desplazamiento hacia el lector, la caída en un subjetivismo que pierde la objetividad del texto, el esfumarse de las preocupaciones epistemológica por el encandilamiento ontológico existencialista, el relativismo, y en definitiva el escepticismo, pues cualquier lectura tiene tanta validez como la otra. El desplazamiento hacia el lector tiene tantos costos, que más conviene volver al autor. Así lo plantea, entre otros, Eric Hirsch con una teoría que pone el acento en la intención del autor y así pretende fijar para siempre el significado de un texto. Se trata de una de las críticas de la hermenéutica en nombre de la epistemología (156). Luego de presentar sus planteamientos, ahondaremos en algunas teorías hermenéuticas que ponen el acento en el polo obra-lector. Son desarrollos en el ámbito literario, que con el específico nombre de "estética de la recepción" de la escuela de Constanza, que otros denominan más ampliamente pragmática, han desarrollado Hans Robert Jauss y Wolfang Iser. Finalmente, en un nuevo desplazamiento, presentaremos los planteamientos de Umberto Eco preocupado por poner límites a la interpretación y a los posibles excesos de sus colegas literatos, que insistiendo unilateralmente en el polo del lector se olviden del texto.

Subyace a este ir y venir del autor al lector pasando por el texto y viceversa, la discusión sobre la tensión objetivismo-relativismo: por un lado, el anhelo que exista una sola interpretación correcta (garantizada por el sentido único que le dio el autor, o por las estructuras inequívocas del texto); por otro, el deseo de una apertura que

(153) Ibíd., 156.

(154) Ibíd., 153.

(155) Ibíd.

(156) Por compartir esta misma dirección cabe mencionar también la hermenéutica metódica Emilio Betti (1890-1968), doctor en jurisprudencia y letras, interesado en "suministrar un canon del comprender como sistemática y metódica de las ciencias del espíritu” (M. Ferraris, ob. cit., 275. La presentación de su teoría hermenéutica en 274-279). 
no pone límites a la hermenéutica, pues cualquier interpretación es tan válida como cualquier otra.

\section{1) El problema de la validez en la interpretación: la vuelta a la intención del autor en E. Hirsch}

Como hemos visto, Gadamer estima que las intenciones del autor nunca agotan el significado de una obra literaria. A medida que la obra pasa de contexto en contexto, cultural o histórico, se pueden extraer de ella nuevos significados nunca previstos ni por el autor ni por el público lector de su época. Es esta indeterminación e incertidumbre lo que causa el rechazo de muchos detractores de la hermenéutica. Tomamos, a modo de ilustración, el caso de E. D. Hirsch con su obra Validity in Interpretation (1967), que en nombre de la epistemología es portavoz de una crítica anglosajona a la hermenéutica. Sin un criterio de validación que ponga a prueba sus resultados la hermenéutica carece de seriedad. "Toda empresa intelectualmente respetable supone un control riguroso de los resultados y un criterio que permita decidir si esos resultados son verdaderos o falsos" (157). Denuncia el carácter ilusorio del círculo hermenéutico que solo suministra pseudo evidencia (158). Para ser operativa una lógica de la validación debe disponer de un criterio normativo absolutamente seguro. Para Hirsch este criterio no es otro que la intención original del autor: "Eliminar el autor original como aquel que determina la significación, quiere decir que se rechaza el único principio que constriñe y que puede dar una validez a una interpretación" (159).

Hirsch no cree que porque el significado de una obra sea idéntico a lo que el autor quiso decir con ella cuando la escribió, esto quiera decir que solo es posible realizar una interpretación del texto. Puede haber un gran número de interpretaciones válidas, pero todas ellas deben moverse dentro del "sistema de las expectativas y probabilidades típicas" que permite el significado que pretendió el autor (160). "Las significaciones pueden variar a través de la historia, pero los significados permanecen constantes. Los autores ponen los significados pero las significaciones las ponen los lectores (...). Lo que uno haga con ese significado, cómo se le emplee, se convierte en una mera cuestión secundaria relacionada con la "significación"” (161). Al identificar el significado de un texto con lo que el autor quiso decir (independientemente de que tengamos acceso a ello), el significado literario es absoluto e inmutable, perfectamente capaz de resistir los cambios históricos (162).

(157) Jean Greisch, "La crise de l'herméneutique. Reflexions méta-critiques sur un débat actuel”, en J. Greisch, K. Neufeld, C. Théobald, La crise contemporaine. Du modernisme a la crise des herméneutiques, Beauchesne, Paris, 1973, 152.

(158) "Se puede comparar estas reflexiones de Hirsch con el violento manifiesto anti-hermenéutico de Hans Albert, Traktat über kritische Vernunf, Köln, Kiepenheuer, 1968, inspirado en la epistemología neopositivista de Karl Popper. (Cf. Greisch, ob. cit., 152). Para una presentación breve de ambos, en relación a la hermenéutica Cf. M. Ferraris, ob. cit., 258-259

(159) E. D. Hirsch, Validity in Interpretation, New Haven and London, Yale University Press, 1971 (2), 5. Citado por Greisch, ob. cit., 154.

(160) Cf. Terry Eagleton, Una introducción a la teoría literaria, FCE, México, 1988, 87

(161) Ibíd. 87 y 89.

(162) Cf. Ibíd., 87. Notemos lo mucho que debe Hirsch a la fenomenología husserliana. 
"El objeto de esta vigilancia es proteger la propiedad privada. Hirsch opina que pertenece al autor el significado que tuvo en mente, y que el lector no debe ni robarlo ni violarlo" (163).

Hirsch reconoce que su punto de vista es realmente muy arbitrario. "No hay nada en la naturaleza del texto que obligue al lector a interpretarlo en conformidad con el significado que le asignó el autor (el autorial); pero si no respetamos el significado autorial nos quedamos sin "norma" de interpretación y corremos el riesgo de abrir las esclusas de la anarquía crítica" (164).

Hirsch opina que la insistencia de Heidegger y Gadamer en que el significado siempre es histórico abre la puerta al relativismo total. Basándose en este argumento, lo que una obra literaria signifique el lunes puede no coincidir con lo que signifique el martes. Resulta interesante especular sobre la razón por la cual Hirsch temió tanto esta posibilidad. "Para detener las sandeces relativistas regresa a Husserl y arguye que el significado no cambia porque sigue siendo siempre el acto intencional de un individuo en un momento dado" (165).

Pero no es necesario ese tipo de fijación, ese clavo, para evitar el relativismo, pues el significado del lenguaje es una cuestión de carácter social. En un sentido verdadero, el lenguaje pertenece a mi sociedad antes de pertenecerme a mí. No soy el dueño que cambia los significados de lunes a martes (166).

\section{2) El problema de la recepción: las teorías y prácticas orientadas al lector}

Los autores representativos de la teoría o estética de la recepción, interesados en describir el efecto que causa una obra de arte en el público, definen su enfoque justamente como una superación de las formas tradicionales de las estéticas de producción y de representación. Desde un punto de vista lingüístico se ha llamado a la teoría de la recepción una "pragmática de los estudios literarios", lo cual enfatiza el punto de vista comunicativo de la obra frente al sintáctico o estructural y semántico (167). Este nuevo énfasis ha sido considerado por algunos como un nuevo paradigma, que "puede ser resumido en la fórmula siguiente: "es solamente en el proceso de lectura que las significaciones de los textos literarios son verdaderamente generadas" (Iser). Lo que el texto introduce en la interacción con el lector no debe ser considerado como un previo estático, sino más bien como una cualidad virtual; la obra literaria no nace más que en la interacción entre el texto y su lector" (168).

Los postulados de los científicos de la "Escuela de Constanza", en torno a Hans Robert Jauss y Wolfgang Iser "renovaron los estudios literarios, liberando al lector en relación con una interpretación de textos centrada predominantemente en

(163) Ibíd., 89.

(164) Ibíd.

(165) Ibíd., 91.

(166) Cf. Ibíd.

(167) Cf. "Introducción” a Dietrich Rall (compilador), En busca del texto. Teoría de la recepción literaria, UNAM, México 1993, 5.

(168) Rebell, "Pragmatique et Nouveau Testament", en Pierre Bühler et Clairette Karakassh, Quand interpréter c'est changer. Pragmatique el tectures de la Parole (Actas congreso Neuchâtel 1994), Labor et Fides, Geneve, 1995, 153. 
los autores o una interpretación inmanente" (169). Con la famosa conferencia inaugural de Jauss en 1966, "Historia literaria como provocación a la ciencia literaria", se abre paso una tendencia orientada hacia el lector, la sociedad, la acción y la comunicación.

Es obvio que fue importante que la Escuela de Constanza destacará el papel del lector en el proceso de comunicación literaria: existía ahí una laguna olvidada tanto por el biografismo como por el análisis inmanente (170). Contribuirá a superar los dos clavos que pretenden fijar el significado de una obra: el romanticismo centrado sobre la intención del autor y el estructuralismo sobre las estructuras del texto (171).

En contra de estas fijaciones, se estima en realidad que el texto no pasa de ser una serie de indicaciones dirigidas al lector, de invitaciones a dar significado a un trozo escrito. "En la teoría de la recepción, el lector "concretiza" la obra literaria. La obra literaria esta llena de "indeterminaciones", elementos cuyo efecto depende de la interpretación del lector, y que pueden interpretarse en un sinnúmero de formas, quizás opuestas entre sí” (172). El teórico polaco Roman Ingarden llama a esto "esquemas" o direcciones generales que el lector debe actualizar. Basta cotejar el concepto de "lector implícito" de Iser con el "lector modelo" de Eco, el "archilector" de Riffaterre o el "lector informado" de Fisch, para darse cuenta cómo se parecen los enfoques críticos (¡y en qué se diferencian!) que tratan de captar las características de esa instancia prevista en los textos y necesaria para darles vida (173).

Junto al trabajo de H. Jauss, tenemos las precisiones de Wolfgang Iser: "Claro que desearíamos saber lo que había en la mente del autor, pero ni él lo sabe por completo. Lo que tenemos a la mano es su obra. No creo que pueda escribirse una Historia de la Literatura basada en la relación obra-lector. Es una divergencia teórica que tengo con mi colega Jauss, que, de hecho, hasta ahora no logró concretizar su interesante propuesta teórica. Tal vez pueda hacerse algo en el caso de que se pase del centrarse en el concepto de "recepción", ahí subyacente al concepto de "eficacia" (174). Eficacia (Wirkung) sería mejor que el término recepción o 'respuesta', pues nos centra en la obra, "en la actuación que la estructura de esta podrá tener en el lector, y no en la respuesta que el lector da a esto" (175). "De este modo, en el momento en que se recibe la Estética de la recepción en el extranjero, el profesor Iser, uno de sus creadores, ya la abandonó, o mejor dicho, evolucionó hacia la Estética de la Eficacia (Wirkungsästhetik), lo que significa una búsqueda de mayor aproximación de la obra, del texto de la obra, examinándose la forma en que la obra se estructura para provocar en el lector determinados efectos" (176).

(169) D. Rall, ob. cit., 6.

(170) Cf. Flavio R. Kothe, "Fragmento para un diálogo sobre literatura”, en Dietrich Rall, ob. cit., 349.

(171) La expresiva imagen para señalar los intentos de fijar (detener, unificar, canonizar) el sentido de un texto es de T. Eagleton: "El siglo XX encierra otro clavo en su arsenal crítico-literario para fijar la obra literaria de una vez por todas. El clavo se denomina estructuralismo" (T. Eagleton, ob. cit., 113).

(172) T. Eagleton, ob. cit., 98.

(173) Cf. ibíd.

(174) Flavio R. Kothe, art. cit., 349.

(175) Ibíd.

(176) Ibíd. 
Con todo, esta evolución no abandona la premisa fundamental de que "la obra literaria no es un ente en sí que exista fuera del tiempo y del espacio", sino que “existe siempre y únicamente en el proceso social de comunicación” (177).

\section{3) El problema de la pluralidad de sentidos y los límites de la interpretación: ni sentido único ni infinitos sentidos}

Las críticas a los planteos de la Escuela de la recepción o de la eficacia, centrada en el lector, no se hicieron esperar. Significados tan múltiples como los contextos de recepción o las peculiaridades de los lectores expone a una indeterminación sin fin el trabajo de interpretación. Saliendo al paso de tales críticas conviene presentar los argumentos de Eagleton, como una introducción a lo que consideramos un último desplazamiento, que incluye los esfuerzos de Umberto Eco, para equilibrar esta lucha entre el autor, el texto y el lector y algunas conclusiones provisorias que nos parecen cercanas al trabajo mediador de Ricoeur.

Eagleton afirma enfático: "Carece de toda justificación afirmar que se puede hacer que un texto literario signifique cualquier cosa (...), idea que no pasa de ser una simple fantasía nacida en la mente de quienes han pasado demasiado tiempo en las aulas. Dichos textos pertenecen al conjunto de una lengua, tienen complicados nexos con otras prácticas lingüísticas, por mucho que las trastornen y violen. En realidad, el lenguaje no es algo con lo cual podamos hacer lo que nos venga en gana (...). Esto es parte de lo que significa que la obra literaria restringe las interpretaciones que de ella hacemos, o que su significado, hasta cierto punto, se halla inmanente en ella. El lenguaje es un campo de fuerzas sociales que nos moldea profundamente. Es un desvarío académico considerar la obra literaria como una palestra de infinitas posibilidades que van más allá de ella misma" (178). Reconociendo que hay textos más abiertos que otros a interpretaciones múltiples, pues "al interpretar un poema se tiene más libertad que al interpretar un aviso del metro (...), la institución académica, el conjunto de formas socialmente legitimadas de leer las obras sirven de freno" (179). Carece de sentido el miedo que algunos padecen de una deriva relativista infinita: "a algunos críticos y estudiantes de literatura les preocupa la idea de que no haya solamente una única interpretación "correcta" del texto literario, aun cuando quizá tampoco haya muchas" (180).

Umberto Eco comienza su libro, Los límites de la interpretación (1990) (181), advirtiendo del cambio de paradigma de las ultimas décadas: "Si con el estructuralismo se privilegiaba el análisis de texto como objeto dotado de caracteres estructurales propios descriptibles mediante un formalismo más o menos riguroso, posteriormente la discusión se orientó hacia una pragmática de la lectura" (182). Se multiplican las teorías sobre la pareja Lector-Autor y surgen por doquier narradores semióticos, extraficticios, sujetos de enunciación, metanarradores y también lectores

(177) Ibíd.

(178) T. Eagleton, ob. cit., 110.

(179) Ibíd.

(180) Ibíd., 112.

(181) U. Eco, Los límites de la interpretación, Lumen, Barcelona, 1992.

(182) Ibíd., 22. 
virtuales, ideales, proyectados, implícitos, metalectores y otros. "Especulaciones diferentes como la estética de la recepción, la hermenéutica, las teorías semióticas del lector ideal o modelo, el llamado reader oriented criticism y la deconstrucción han elegido como objeto de investigación no tanto los acontecimientos empíricos de la lectura (objeto de una sociología de la recepción) como la función de construcción del texto -o de la deconstrucción- que desempeña el acto de lectura, visto como condición eficiente y necesaria de la misma actuación del texto como tal" (183). Lo común en estas tendencias es subrayar, "además o en vez del momento generativo, el papel desempeñado por el destinatario en la comprensión, actualización e interpretación del texto, así como la manera en que el texto mismo prevé esta participación" (184). En síntesis, "el fantasma del lector se ha introducido en el centro de diversas teorías, por filones independientes" (185).

Frente a este fantasma Eco defiende la posibilidad de una interpretación según la intención del texto o intentio operis. Esta noción desempeña un papel importante como fuente de sentido que, aunque no es "reducible a la pretextual intentio auctoris, actúa como restricción sobre el libre juego de la intentio lectoris" (186). Eco comentará casos, en los que el exceso de interpretación produce un derroche de energías hermenéuticas que el texto no convalida. Inversamente, se intentan sugerir los criterios de economía aplicables a la lectura de los textos como mundo o del mundo como texto (187). "Ese mínimo esfuerzo es el que podría ser aceptado por una comunidad de intérpretes decidida a alcanzar algún acuerdo, si no sobre las interpretaciones mejores, al menos sobre el rechazo de las insostenibles" (188). En otras palabras, y en otro libro Eco sostiene: "Creo... que podemos aceptar una especie de principio popperiano según el cual si no hay reglas que permitan averiguar qué interpretaciones son las "mejores", existe al menos una regla para averiguar cuáles son las "malas" (189). Las restricciones a los intérpretes son impuestas por el mismo texto interpretado. "Los límites de la interpretación coinciden con los derechos del texto (lo que no quiere decir que coincidan con los derechos de su autor)" (190).

Frente a posibles detractores que pueden objetar un cambio en su posición, Eco se defiende: "Puede parecer que, si entonces (con Obra abierta de 1962) celebraba una interpretación "abierta" de las obras de arte, admitiendo que aquella fuera una provocación "revolucionaria", hoy en cambio, me atrinchero en posiciones conservadoras. No creo que sea así. Hace 30 años... me preocupaba de definir una especie de oscilación, o de inestable equilibrio, entre iniciativa del intérprete y fidelidad a la obra. En el curso de esos 30 años, alguien se ha decantado en exceso en pro de la vertiente de la iniciativa del intérprete. El problema ahora no es decantarse en sentido opuesto, sino subrayar, una vez más, la ineliminabilidad de la oscilación" (191).

(183) Ibíd.

(184) Ibíd

(185) Ibíd., 23

(186) Stefan Collini, "Introducción: interpretación terminable e interminable", en U. Eco, Interpretación y sobreinterpretación, Cambridge University Press, 1995 (or. ing. 1992), 11.

(187) Cf. U. Eco, Los límites de la interpretación, ob. cit., 16.

(188) Ibíd.

(189) U. Eco, Interpretación y sobreinterpretación, ob. cit., 55.

(190) U. Eco, Los límites de la interpretación, ob. cit., 19.

(191) Ibíd., 19. 


\section{A MODO DE CONCLUSIÓN}

La hermenéutica y la teoría de la recepción han contribuido a que el polo de la interpretación se desplace desde el polo autor-texto al polo texto-lector. Pero el énfasis en la lectura se puede decir de muchas maneras. Luego de recordar lo que al respecto nos dice Ricoeur con la noción de apropiación, hemos presentado las posiciones de un debate del que queremos aprender cómo se puede escapar tanto al objetivismo como al relativismo (un sentido único y fijado para siempre versus todos los sentidos son posibles). Frente a una intentio lectoris radicalizada en manos de algunos teóricos que sostienen que cualquier interpretación es legítima, hemos presentado la reacción de Hirsch que vuelve a la intentio autoris, los desarrollos de la Escuela de Constanza de una estética de la recepción (Jauss) a una estética de la efectividad (Iser), y las preocupaciones de Eco al afirmar la intentio operis. Paradójicamente como todo asunto hermenéutico, la cuestión está abierta.

Sin embargo creemos que la postura de Eco apunta en la dirección correcta, al negar tanto la univocidad como la arbitrariedad en la interpretación de los textos. Su preocupación es compartida por muchos otros y puede ser formulada con la siguiente pregunta: "si el acto de lectura crea cada vez el sentido del texto actualizando las potencialidades de este último y acabando con su indeterminación, ¿cómo la lectura puede ser sustraída a lo arbitrario?" (192). Inspirándose en Umberto Eco, J. Zumstein entrevé aquí la posibilidad de someter las lecturas a un proceso de falsificación: "no es posible determinar la verdadera lectura, pero es posible detectar las lecturas falsas, e.d., aquellas que no respetan las restricciones impuestas por el texto mismo a su interpretación" (193).

En concordancia con estas posiciones podemos resumir lo dicho con la sencilla tipificación que hace de las hermenéuticas el filósofo mexicano, Mauricio Beuchot, en unívocas, equívocas y analógicas. "Las unívocas son las que pretenden hallar a toda costa el significado total y completo de un texto, presentando una sola interpretación como válida; todas las otras tienen que padecer, hundiéndose en el mar de la falsedad. Las equívocas abren demasiado el margen de validez de las interpretaciones, llegando a pretender que todas son válidas, o al menos la gran mayoría, o quizás diciendo que no se puede demostrar que una de ellas sea falsa. En cambio la hermenéutica analógica, a pesar de que abre el espectro de las interpretaciones válidas, dando cabida a más de una, no llega, sin embargo, a permitir a todas en esa categoría; es posible discernir" (194).

Creemos que la obra de Ricoeur comparte esta vía intermedia entre Escylla y Caribdis. A esa conclusión llega Dan Stiver en su notable trabajo sobre 'la teología después de Ricoeur': nuestro filósofo ha contribuido a abrir un camino que va más allá del objetivismo de la modernidad sin caer en el supuesto relativismo de la

(192) Pierre Bühler, "L’interpréte interpreté", en Pierre Bühler et Clairette Karakassh, Quand interpréter c'est changer. Pragmatique el tectures de la Parole (Actas congreso Neuchatel 1994), Labor et Fides, Geneve, 1995, 246.

(193) Ibíd.

(194) A. Alvarez Balandra, "Hermenéutica analógica y procesos educativos”, Analogía Filosófica, Número especial 10, México, 2002, 11. 
posmodernidad (195). Entre el sujeto 'ensalzado' de Descartes y el sujeto 'humillado' de Nietzsche (196), un Cogito 'herido', apto para nuestra modernidad, que algunos ya estiman superada y que otros ven plenamente vigente. "Modernidad quebrada" para algunos, "modernidad solamente herida" para otros (197). La reivindicación que Ricoeur hace de la subjetividad me parece que lo ubica entre estos últimos, abriendo un camino intermedio apto para mediar y articular tanto las búsquedas de Habermas como las de Derrida, un camino que pudiera ser transitado tanto por los discípulos del psicoanálisis como por los del estructuralismo. Es a lo que apunta esta variante hermenéutica de una tradición reflexiva y fenomenológica continuamente desplazada. Una senda por la que intentan caminar muchos, propicia para filósofos y teólogos: 'más allá de la objetividad y del relativismo', al decir del filósofo Richard Bernstein, o 'más allá del fundacionalismo y el relativismo' en la expresión del teólogo David Tracy (198).

\section{RESUMEN}

El artículo presenta el aporte de Ricoeur a la filosofía hermenéutica en base a una serie de desplazamientos que su pensamiento ha provocado. Los tres primeros se ocupan de mostrar los desplazamientos que han afectado a las tradiciones de las que nuestro filósofo se siente deudor. En primer lugar la tradición reflexiva salida de Descartes que, por los años sesenta ha recibido el fuego cruzado del psicoanálisis y del estructuralismo cuestionando un sujeto que después de la batalla queda como un Cogito 'herido'. En segundo lugar los cuestionamientos a la tradición hermenéutica nuevamente combatida desde dos frentes, la teoría crítica y la deconstrucción. En tercer lugar los desplazamientos que el propio Ricoeur ha hecho respecto de la fenomenología, y que pueden ser presentados desde dos movimientos que le son característicos: la incorporación en su filosofía del giro lingüístico y el injerto de la hermenéutica en el método fenomenológico. Son estos desplazamientos respecto de las propias tradiciones que lo constituyen -reflexiva, hermenéutica, fenomenológica- los que permiten abordar en el cuarto acápite una adquisición fundamental de su filosofía hermenéutica y que se constituye en un aporte insustituible para todas aquellas disciplinas -entre ellas la teologíaque viven interpretando: el desplazarse desde una hermenéutica del autor a una hermenéutica

(195) Así lo afirma Nancy Lammers Gross, en la presentación que hace de la obra de Dan Stiver: "In his conclusion, Stiver claims that Ricoeur opens a new way of doing theology that goes beyond the objectivism of modernity without falling prey to what many understand-mistakenly, according to Stiver-as the relativism of postmodernity, which embraces pluralism and leads inexorably to praxis" (N. Lammers, Theology Today, Princeton, Oct 2002, Vol 59, 521.

(196) Cf. Ricoeur, "Prólogo" a Soi-même comme un autre, Paris, Seuil, 1990, XXVIII.

(197) Así Margit Eckholt que vincula el quiebre de la seguridad de sí del "ego cogito" de Descartes a lo que denomina "modernidad quebrada". Ante las experiencias que ha provocado dicho quiebre, "aferrarse a la razón ilustrada sin la confesión de su dialéctica, sería expresión de una ingenuidad que no admite disculpas". El camino de Ricoeur que va tras las huellas del pensamiento occidental, permitiría asomarse a la fractura de lo moderno; "un camino que -justamente ante la infinitud de ofertas, la perspectividad y la fragmentación posmodernas- no puede dejar de buscar la "unidad de la razón" (M. Eckholt, "Reflexión teológica con Paul Ricoeur. De la modernidad quebrada hacia una nueva comprensión de la cultura", Proyecto 36 (2000) 209-210.

(198) Cf. Richard Bernstein, Beyond objectivism and relativism: Science, Hermeneutics, and Praxis, Basil Blackwell, Oxford, 1983 y David Tracy, "Beyond foundationalism and Relativism. Hermeneutics and the New Ecumenism", On naming the Present, New York, 1994, 131-139; Trad. Cast.: “'Mas allá del fundacionalismo y el relativismo? La hermenéutica y el nuevo ecumenismo", en Concilium 2, abril 1992, 343-353. 
del lector que actualiza el texto en el acto de lectura. Finalmente, en el quinto acápite se abordan algunas de las consecuencias de este desplazamiento, mostrando que Ricoeur contribuye a abrir una vía intermedia entre un sentido único y fijo para siempre y sentidos infinitos inconmensurables entre sí, un camino que permite superar el objetivismo moderno evitando el relativismo posmoderno.

\begin{abstract}
The article present's Ricoeur's contribution to the hermeneutic philosophy, on the grounds of some movements brought about by his thought. The first three movements focus on those aspects which affected the traditions to which the author feels indebted. First, the reflexive tradition deriving from Descartes, which in the 70's was updated by its merge with psychoanalysis and structuralism, putting to quiestion the subject which turns into a cogito 'wounded' after the battle. Second, the objections to the hermeneutic tradition fought from two sides; critical theory and descontruction. In the third place, Ricoeur's own movements regarding phenomenology: the introduction of the linguistic shifts into philosophy and the introduction of the hermeneutic in the phenomenological method. These three movements -reflexive, hermeneutic and phenomenological- set the grounds for the $4^{\text {th }}$ section, which looks at the fundamental acquisition of his hermeneutic philosophy which constitutes a unique contribution to the disciplines -theology among them- which rely on interpretation: going from the author's hermeneutics to the resder's hermeneutics who actualizes the text as he reads it. Finally, in the $5^{\text {th }}$ section some of the consequences of such movements are discussed stating that Ricoeur's contribution opens an intermediary path between a unique and fixed sense and infinite senses beyond measure. His path allows to overcome the modern objectivism while keeping away from the postmodern relativism.
\end{abstract}

